\title{
A ESTIRPE ALBANESA DE LA VIRGEN DEL REFUGIO DE LA TRINIDAD: SOBRE UN VIEJO ICONO CASI OLVIDADO
}

\author{
DANIEL BENITO GOERLICH \\ Universitat de València \\ Daniel.Benito@uv.es
}

\begin{abstract}
Resumen: Este estudio investiga sobre el estado actual y el misterioso origen de un icono muy antiguo conservado en el Monasterio de la Trinidad de Valencia y su vinculación con Donica Adrianiti, esposa de Giorgio Castriota (Gjergj Kastrioti) Scanderbeg, considerado héroe nacional de Albania; también sobre la presencia y estancia de esta noble dama en Valencia en relación con la reina Juana de Nápoles, hermana de Fernando el Católico.
\end{abstract}

Palabras clave: Donica / Andrónica / Scanderbeg / Castriota / Albania / icono / Monasterio de la Trinidad de Valencia / Juana de Aragón / Juana de Nápoles / Giorgio Castrioto / Gjergj Kastrioti.

\section{THE ALBANIAN LINEAGE OF THE VIRGIN OF THE REFUGE OF THE TRINITY ON AN OLD ALMOST FORGOTTEN ICON}

Abstract: This study investigates the current state and the mysterious origin of a very old icon preserved in the Monastery of the Trinity of Valencia, and its link with Donica Adrianiti, wife of Giorgio Castriota (Gjergj Kastrioti) Scanderbeg, considered as the national hero of Albania. It also studies the presence and the stay of this noble lady in Valencia in relation with Queen Juana of Naples, sister of Fernando el Católico.

Key words: Donica / Andrónica / Scanderbeg / Castriota / Albania / icon / Monastery of the Trinity of Valencia / Joan of Aragon / Joan of Naples / Giorgio Castrioto / Gjergj Kastrioti.

En el Monasterio de la Trinidad de Valencia ${ }^{1}$ se conserva un antiguo icono, intitulado bajo la advocación de Nuestra Señora del Refugio, ${ }^{2}$ que si bien ha recibido allí culto notable y gran veneración desde los principios del siglo XVI hasta la actualidad y cuenta con una cofradía propia, varias veces refundada, permanece oculto desde hace doscientos años bajo un repinte moderno que lo cubre por entero. Sus orígenes confusos y hoy casi olvidados, lo vinculan con la estirpe de Jorge Cas- trioto Scanderbeg, héroe nacional albanés, célebre en toda Europa por su guerra constante contra los turcos en defensa de su patria y concretamente con una mujer de su estirpe y familia que habría traído el cuadro a Valencia y mandó colocarlo sobre su sepultura. Sobre quién pudo ser esta dama se ha especulado mucho. Algunos quieren ver en ella a Andrónica (Donica) esposa del líder albanés, otros a su "nuera" Giovanna, ${ }^{3}$ otros finalmente optan por María Zardarí, sobrina de

\footnotetext{
* Fecha de recepción: 15 de octubre de 2019 / Fecha de aceptación: 30 de abril de 2020.

1 BENITO GOERLICH, Daniel. El Real monasterio de la Santísima Trinidad de Valencia. Historia y Arte. Valencia: Consell Valencià de Cultura, 2008.

2 "tan esclarecida por los favores que su capilla dispensa, como oscuro el cierto principio que tuvo, i que solo puede traslucirle por congeturas". SALES, Agustín. Historia del Real Monasterio de la SSma Trinidad, Religiosas de Santa Clara, de la regular observancia, fuera los muros de la Ciudad de Valencia. Valencia: Josef Estevan Dolz, 1761, p. 111.

${ }^{3}$ Como veremos Agustín Sales supone que la esposa del hijo de Scanderberg se llamaría Giovanna, pero la única nuera de Andrónica fue Irene Brancovic.
} 
Andrónica y nodriza de Juana IV de Nápoles. ${ }^{4}$ No sabemos si al final de estas consideraciones se podrá afirmar con alguna seguridad cuál de estas tres damas es la relacionada con el cuadro y la mencionada sepultura.

En todo caso, no es esa la única tumba vinculada al linaje de Scanderbeg que existe en el monasterio valenciano, porque Alonso Castrioto, un muchacho casi adolescente, muerto accidentalmente en 1503, en confusas circunstancias, fue enterrado allí, en un túmulo de mármol, ${ }^{5}$ del cual subsiste una lápida, en la capilla del lado de la epístola lindante al coro, donde está inscrito:

Aquí lace/ Alfonso, Hijo del famoso Georgio/Castrioto, Rey de Albania; AÇOTE de/ los Turcos, Y MURO IneXPUgnaBLE DE/LA CHRISTIANDAD, A QUIEN LLAMARON/LOS TURCOS ESCARDARBECH, Y A QUIEN POR/ SU DESCENDENCIA, VALOR Y MAGNITUd de/Animo le Comparaban al Rey Ale/XANDRo de Macedonia. Murio de/edAd de 15 Años en esta CiUdad Ide Valencia, AÑo 1503

El cronista Agustín Sales, en 1761, en su extensa y erudita historia del monasterio de la Trinidad, al comentar las más importantes y preciadas advocaciones sagradas que allí se veneraban indica que:

permanece en la misma Iglesia la Santa Imagen de María SS del Refugio, tan esclarecida por los favores que en su Capilla dispensa, como oscuro el cierto principio que tuvo, i que solo puede traslucirse por conjeturas: bien que mi aplicación en este assunto ha encontrado pruebas bastante robustas para hacer ya moral certidumbre. De memorias que conservaba este Real Monasterio, nos expuso assi la tradición de esta Santa Imagen el P. Gerónimo Sánchez del Castellar que usò de ellas, como dice en su Chronica MS. Trájola (dice) a este Convento, de Bohemia una llustre Señora que se llamaba la Scandalberta, deuda de los Reyes de Bohemia. La qual con la Reina salió huyendo, quando los Moros se apoderaron de aquel Reino, i murió en batalla el Rei. Acompañando a la Reina hallaron esta Imagen de nuestra Señora en un Monte, con una cuchillada que le avian dado en el rostro los Enemigos de Dios. Aportaron a Valencia estas señoras, con la Imagen que avian hallado. Murió la Scandalberta, i dejó en su testamento que la
Imagen de nuestra Señora la diessen a las Religiosas de este Convento de la SS Trinidad, i que pusiessen en el puesto, en que estuvo muchos años, del estribo de la Capilla de los Santangeles y mandó que sepultasen su cuerpo a los pies de dicha Imagen. ${ }^{6}$

Advertimos varias cosas interesantes en esta narración. En primer lugar que Sales manda imprimir la palabra "memorias", en cursiva, como para descalificarlas o dudar, puesto que después de haber escrito la documentada y erudita historia del monasterio él no las ha visto:

"Todo esto dejó escrito el P. Sánchez que vio las memorias, i Relación que de este assunto tenía el Monasterio, i ahora no están" (p. 113) y por eso escribe "conservaba" y no "conserva": Asimismo cita como manuscrita (MS) la crónica de Gerónimo Sánchez en la que se recogen esas memorias, texto que tampoco ha llegado hasta nosotros. La Capilla de los Santangeles que estuvo dedicada al Arcángel San Miguel y era propiedad de la familia de conversos del financiero Luis Santángel, se abre en la nave de la iglesia, la primera del lado del evangelio, por lo que el estribo al que se refiere ese texto respecto a la colocación del icono y el lugar de la tumba de su dueña es sin duda el espacio del pilar de esa capilla recayente hacia la sepultura de la Reina María de Castilla, fundadora del monasterio. Sobre la cuchillada en el rostro de la Virgen, que la asemeja al icono de Chestokova, palladium de los polacos, nos cuenta Sales un milagro recogido por Sánchez. Al parecer la propietaria del icono contrato a los mejores pintores valencianos y ninguno pudo cubrir el tajo del cuchillo, que se cerró por sí mismo cuando los cristianos volvieron al reino de Bohemia.

Pero las cuestiones más importantes se ofrecen acusadamente intrigantes: primera ¿quién era esa misteriosa dama extranjera, Scandalberta?, segunda ¿qué tenía que ver con la reina de Bohemia? Y finalmente ¿por qué razón ambas vinieron a Valencia? Agustín Sales se esfuerza por aclarar estos asuntos y presume de haberlo resuelto: "Yo tengo la sustancia de dicha tradición del Monasterio por constante, pero son otras las circunstancias" (p 113). Sales desarrolla sus argumentos a partir de la historia del matrimonio del rey Ladislao Jagellón de Bo-

\footnotetext{
4 "Se refiere aquí a la antigua nodriza de su hija Juana, María Zardari Scanderbeg, nodriza de Juana IV de Nápoles, que siguió a las reinas en su viaje a España cuando estas se trasladaron allí, a la corte de los Reyes Católicos. Murió en Valencia donde estaba sepultada en el Real Monasterio de la Santísima Trinidad". PERUGINI, Carla; MARTínEZ GÁZQUEZ, José. "Testamento de Doña Juana III, Reina de Nápoles". Butlletí de la Reial Acadèmia de Bones Lletres de Barcelona, 1992, Vol. 43, p. 105, nota 72.

5 "Y entre otras cosas singulares, tiene en un túmulo de piedra mármol debaxo del coro, encaxado en la pared, el cuerpo del hijo de aquel famoso Georgio Castrioto, Ilamado Escandemberg, Rey de Albania, açote de los Turcos, y muro inexpugnable de la Cristiandad; el qual murió desgraciadamente en Valencia pasando a la corte." ESCOLANO, Gaspar. Década primera de la historia de la insigne y Coronada ciudad y Reyno de Valencia, Vol. I, libro V, cap. IX, col. 951. Valencia: Pedro Patricio Mey, 1610.

${ }^{6}$ SALES, Agustín, 1761 (véase nota 2), p. 111 y 112.
} 
hemia con Beatriz de Aragón, ${ }^{7}$ hija de Ferrante I de Nápoles, y su primera esposa y reina de Hungría por su anterior unión, en 1476, con Matías Corvino de Hungría, que había fallecido en 1490. Este matrimonio duró poco, pues, una vez coronado Ladislao rey de Hungría, la repudió y Beatriz volvió a Nápoles. Pasa a citar entonces la historia de Jorge Castrioto Scanderbeg "Rei de Albania y el Epiro, i uno de los mayores, i más afortunados Capitanes del mundo" (p. 114) y como a su muerte, que fecha erróneamente en 1466, su mujer Andrónica y su hijo, muy pequeño, Juan Castrioto, se refugiaron en Nápoles, donde, acogidos por el rey Ferrante I, se les concedieron feudos y honores:

Puestos Madre, i hijo en Italia en las tierras que les tocavan por juro de heredad, y avia tenido Jorge, andando los tiempos, este Juan Castrioto casose con una Señora de allí, la qual a cabo de tiempo quedó Viuda, i fue Madre de Don Alonso Castrioto (...) I ésta, según se sigue de los 15 años de edad que expressa la Sepultura de Don Alonso, quedó Viuda en el año 1487. Esta Señora Viuda i tan principal en el Palacio de Nápoles, es sin duda la Scanderberga, que tomó el timbre de su Suegro, que en lo civil se reputa Padre, para distinguir su hidalguía. Esta es la que hallándose Viuda fue enviada por Fernando I (...) por Dama de su hija Doña Beatriz, reina entonces de Ungria, i después de Boemia. ${ }^{8}$

Sigue explicando Sales que esta mujer, en compañía de la reina Beatriz, encontraría la "Imagen del Refugio profanada", y que junto con algunos criados bohemios, sepultados en el patio del monasterio, vino a Valencia en 1499, acompañando a Juana de Aragón, reina viuda de Nápoles, hermana de Fernando el Católico, con un hijo llamado Alonso. Incluso cita un asiento de mayo de 1504 del hoy perdido Libro de Entradas por donde cree que se podría averiguar su nombre:

Ítem del Cos de la Señora na Juanota, CIII s. Ítem de Oferta XXI s. Los napolitanos assi llamaban a Juana. Lo cierto es que la Scanderberga fue sepultada en la Sepultura de los Santangels, o por deudo o amistad íntima con esta familia Valenciana que había servido

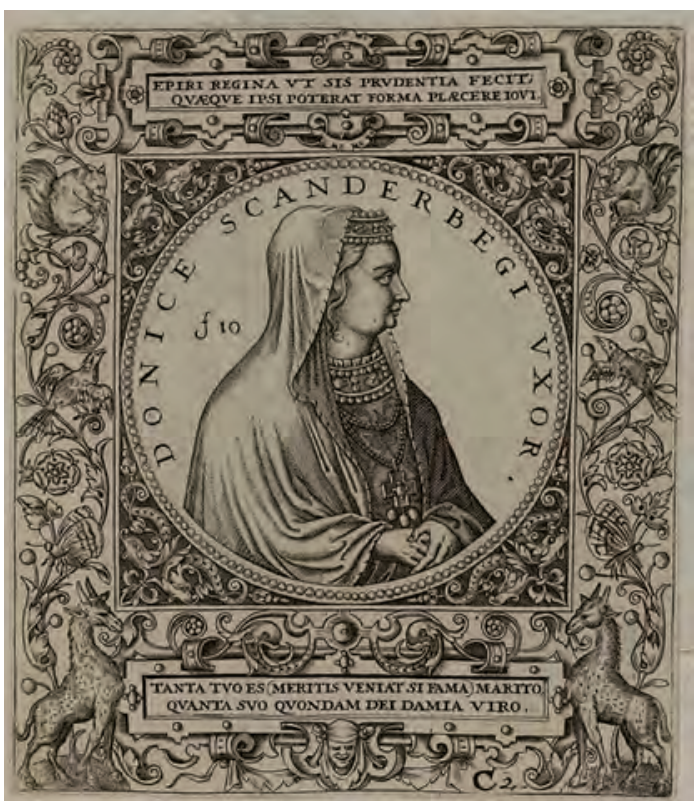

Fig. 1. Retrato de Andrónica (Donika) Castriota, grabado por Johann Theodor de Bry, 1596, Fürstlich Waldecksche Hofbibliothek Bad Arolsen.

en el Palacio de Nápoles de donde la conocía: sepultose a los pies de la santa Imagen del Refugio que trajo a Valencia en su compañía. ${ }^{9}$

Respecto a la inscripción en la lápida de la tumba de Alonso Castrioto, Sales señala: "Todos se equivocaron, sin reparar el anacronismo" (p. 117) puesto que si Jorge Castrioto Scanderbeg murió en 1466 no podría tener un hijo de 15 años en 1503. "pero una memoria coetánea, que nunca vieron esos Autores, le hace Nieto del famoso Jorge Príncipe de Albania, i quita toda dificultad al asunto, dejando la cosa en su ser verdadero" (p. 119). Acaba Sales trascribiendo en su apoyo una larga cita del libro sobre las guerras de los turcos del valenciano Vicente Roca, sobrino de Carlos Roca, camarero del

\footnotetext{
7 En la época de Beatriz de Aragón (1457-1508), princesa napolitana, hija de Ferrante I y su primera esposa Isabel de Chiaromonte, fue prometida por su padre el rey de Hungría, Matías Corvino, porque en aquel entonces ese reino tocaba al mar Adriático. Tras su boda, en 1476, a los 17 años, y durante su primer reinado en Hungría había aportado a aquel país las novedades de renacimiento, que tuvo allí un pronto y floreciente desarrollo. Pero a la muerte sin sucesión legítima de su esposo, y aunque aspiraba al trono su hijo ilegítimo Juan Corvino, Beatriz apoyó la candidatura de Ladislao Jagellón de Bohemia, que fue coronado con la condición de desposarla. Sin embargo, Ladislao, tras asegurar su situación, quiso dar fin al efímero segundo matrimonio y al reinado de Beatriz. Pidió y obtuvo del papa Alejandro VI la anulación del enlace y la repudió. Beatriz volvió a Italia en 1504, se estableció en Pozzuoli, cerca de Nápoles, y en 1506, con el regreso de las reinas viudas Juana III y IV, se estableció con ellas en el Castel Capuano, hasta su muerte el 13 de septiembre de 1508. Fue enterrada en la iglesia de San Pietro Mártir. BERZEVICZY, Alberto. Beatrice d'Aragona. Milán: Dall'Oglio editore, 1974.
}

8 SALES, Agustín, 1761 (véase nota 2), p. 115.

9 SALES, Agustín, 1761 (véase nota 2), p. 117. 

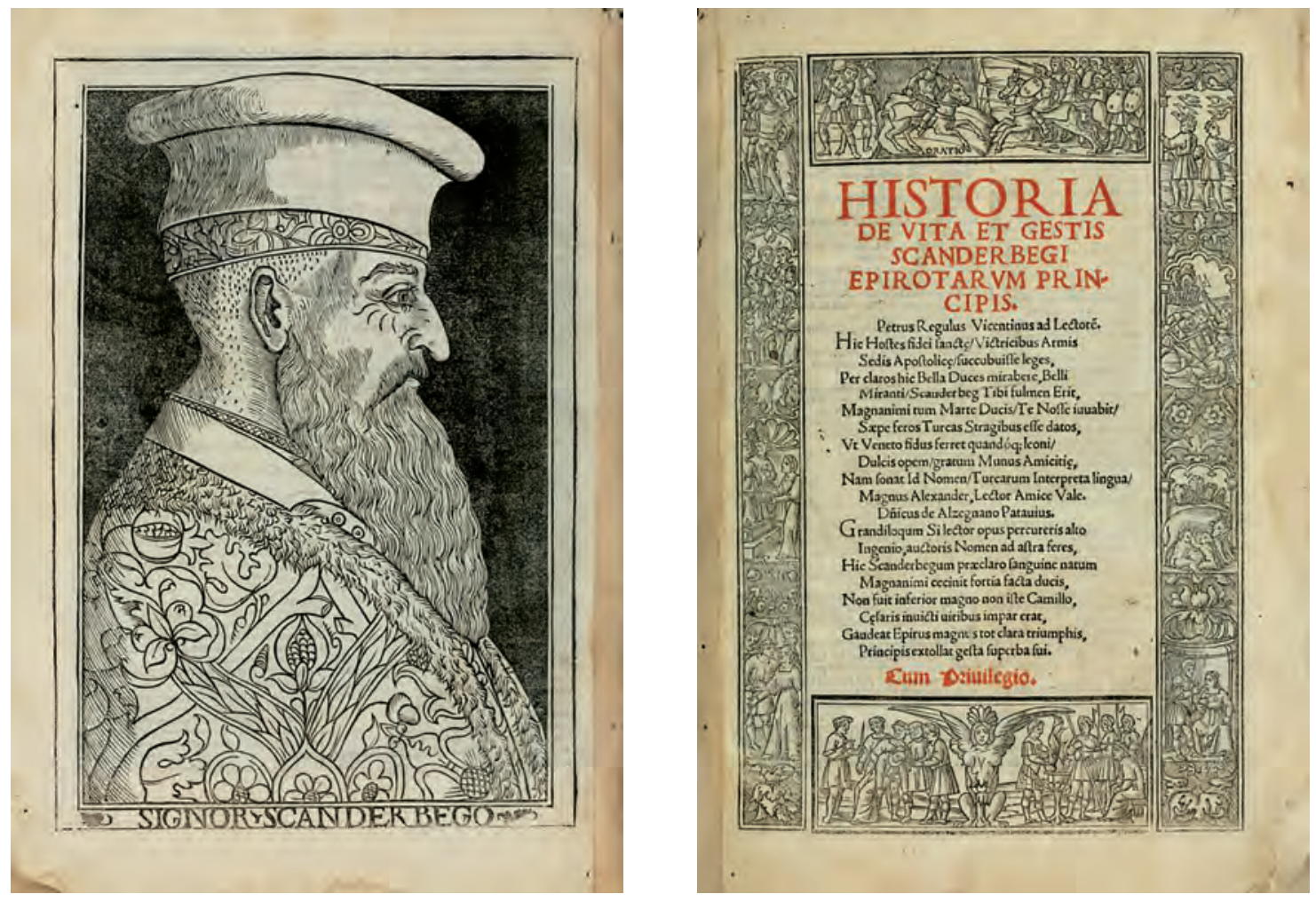

Fig. 2a-b. Retrato de Jorge Castrioto Scanderbeg y portada en Historia de vita et gestis Scanderbegi epirotarum principis de Marino Barlezio, h. 1510.

papa setabense Alejandro VI, que en uno de sus capítulos contiene una breve relación sobre Scanderbeg de la que entresacamos que:

Dexó solo un hijo legitimo llamado Juan Castrioto (...) el desposeído Mancebo, se vino a las tierras del rei Don Hernando dio a su Padre en el Reyno de Nápoles, y casose con una Señora de allí, la qual a cabo de tiempo quedo viuda, y vínose con un su hijo Mancebo llamado Don Alonso Castrioto a esta Ciudad de Valencia con la Reyna Doña Juana de Nápoles: i el año MDIII, ruando el desdichado mozo sobre una mula por las calles, se puso entre medias de unos hombres que se acuchillaban, y por desastre recibió una estocada, del qual murió a las pocas horas, y está enterrado en el Monasterio de la Trinidad debaxo del Coro. ${ }^{10}$
Así pues, quedamos en que en la iglesia de la Trinidad se conserva la tumba de un "nieto" de Scanderbeg y que posiblemente, según Sales, la misteriosa Scanderberga sería una Giovanna, esposa italiana de Giovanni Castrioto Scanderbeg. ${ }^{11}$ Más adelante sigue escribiendo que ella dio a las monjas la imagen ${ }^{12}$ de la Virgen del Refugio: "que trajo de Bohemia a Nápoles y de allí a Valencia". Pero para intentar aclarar lo sucedido hay empezar teniendo en cuenta que, desde su instalación en el Reino de Nápoles, el linaje de los Castriota se divide en dos ramas, que descienden de los dos hermanos Stanisto (Estanislao) y Giorgio (Jorge) Scanderbeg. De Giorgio desciende la línea directa

10 ROCCA, Vicente. Hystoria en la qual se trata de la origen y guerras que han tenido los Turcos, desde su comienço hasta nuestros tiempos, con muy notables sucesos que con diversas gentes y nasciones les han acontecido: $y$ de las costumbres y vida d'llos. Valencia: 1556, Libro I, cap. XXXI.

11 No he podido encontrar acomodo a este "nieto" de Scanderbeg en los árboles genealógicos existentes. La caligrafía empleada en la lápida no parece ser de 1500 sino del siglo XVII y la noticia más antigua del suceso que he encontrado se remonta a Escolano (1610). Por otro lado, la esposa del hijo de Scanderbeg no fue ninguna Giovanna italiana sino Irene Brancovic.

12 "Llamavase nuestra Señora de Gracia: i un devoto suyo Poeta encomendándose mucho a ella para hacer en servicio suyo unos versos, dice la Relación, que a la noche siguiente viò entre sueños, i oyò que le mandava la Virgen le pusiesse el sobre nombre del Refugio de Pecadores. Hace muchos milagros" SALES, Agustín, 1761 (véase nota 2), p. 112. 
Scanderbeg, y de Stanisto descienden los Castriota Branai, que también usaron con frecuencia el prestigioso apelativo Scanderbeg y cabe señalar que en ambas ramas de los Castriota abundan los Giovanni y Giovanna de diferentes generaciones y que la confusión entre ellos en diversos documentos resulta inevitable. La verdad es que al escribir sobre este tema me retrae la complejidad de los árboles genealógicos y las confusas noticias de esa familia. Llegados a este punto es necesario conocer algo más sobre Scanderbeg y sus peripecias y las de su familia más directa y también intentar averiguar cuándo y por qué vino la reina Juana de Nápoles a Valencia y qué familiares de la noble estirpe albanesa podemos identificar entre sus acompañantes.

Estricto contemporáneo de Janos Hunyadi (14071456), que se enfrentó igualmente a los turcos para defender sus tierras, Jorge Castrioto (1405-1468) conocido como Scanderbeg, que significa literalmente Señor Alejandro en referencia a Alejandro Magno y como homenaje a su capacidad militar, dirigió una tenaz resistencia al avance imperialista de los turcos otomanos desde su fortaleza de Kruja (Krujë), apoyado por los agricultores y pastores guerreros de las tierras altas de Albania. El levantamiento promovido por Scanderbeg constituyó el mayor desafío a la ocupación otomana de los Balcanes y su recuerdo ha sobrevivido siglos. Disfruta de una fama imperecedera como campeón de la libertad albanesa. Calixto III lo proclamó en 1457 Atleta Christi, ${ }^{12 b i s}$ título refrendado por sus inmediatos sucesores y después de su muerte, sus hazañas, alabadas por el humanismo renacentista, alcanzaron gran resonancia en toda Europa, afirmándole como héroe nacional de varios pueblos del levante mediterráneo; todavía en la actualidad su memoria provoca intensos sentimientos en los Balcanes y en los numerosos países de la Arberia italiana. ${ }^{13}$

De la estirpe de héroe albanés y de sus peripecias vitales se han ocupado directa o indirectamente diferentes autores antiguos y modernos. La primera biografía fue obra en latín de Marino Barlezio (c. 1455-1513), un sacerdote católico natural de Scutari (Shköder) casi contemporáneo de Scanderbeg, aunque sus noticias las recogió de oídas. El li-

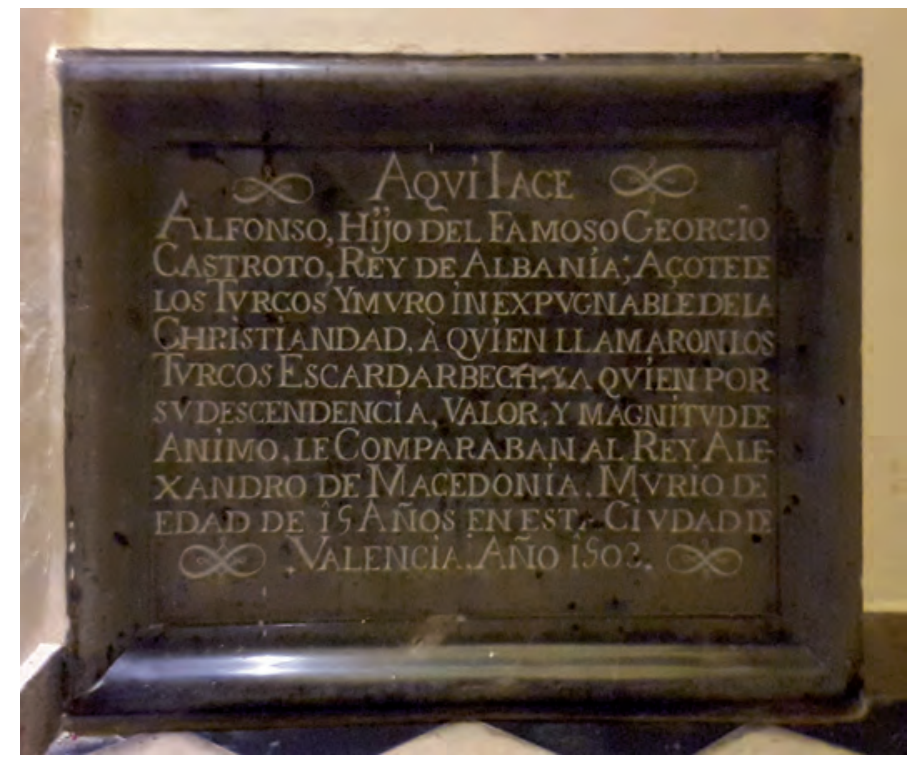

Fig. 3. Lapida sepulcral de Alfonso Castrioto en el Monasterio de la Santísima Trinidad de Valencia.

bro se publicó en Roma hacia 1510, con un magnífico retrato de estampa a toda página de Scanderbeg y fue dedicado a Ferrando Castriota "eius nepotem". ${ }^{14}$ Esta obra pionera fue objeto de muchas ediciones, enseguida traducida a prácticamente todos los idiomas y tuvo una impresionante difusión en toda Europa, sirviendo además de base a muchas otras posteriores, como la francesa de Jacques de Lavardin, Seigneur de Plessis-Bourrot, ilustrada con excelentes grabados, que también fue reiteradamente editada. Otra biografía significativa es la Istoria di Giorgio Castrioto detto Scander-Begh de Gianmaria Bienmi, publicada en $1746,{ }^{15}$ muy utilizada por muchos biógrafos e historiadores posteriores, aunque esta obra ha sido muy cuestionada por Kasem Biçoku en su Gjergj Kastrioti Skkënderbeu: bibliografi 1454-1835, publicada en albanés en 1997. ${ }^{16}$ Las abundantes referencias a Scanderbeg en textos de carácter general sobre la historia del Imperio Otomano y del Mediterráneo oriental y en estudios particulares culminan en la obra de referencia, publicada en $1947^{17}$ por Fan Stylian Noli (1882-

\footnotetext{
12bis NAVARRO, Miguel. Calixto III Borja y Alfonso el Magnánimo frente a la Cruzada, Valencia, 2003, p. $173-174$.

13 Área referente a la minoría etnolingüística albanesa en Italia.

14 Se trata de un sobrino nieto de Scanderbeg, hijo de su hermano Brano Castrioto y por tanto de la línea de los Castriota Branai/Granai.

15 BARLETIUS, Marinus. Historia de vita et gestis Scanderbegi Epirotarum principis, B.V. (Bernardino dei Vitali) Roma, h. 1510; LAVARDIN, Jacques de. Histoire de Georges Castriot Surnommé Scanderbeg, Roy d'Albanie, Paris: Denys Moreau, MDCXXI BIEMMI, Gianmaria, Istoria di Giorgio Castrioto detto Scander-Begh. Brescia: Dalle Stampe di Gianmaria Rizzardi, MDCCXLVI.

16 BIÇOKU, Kasem. Gjergj Kastrioti Skkënderbeu: bibliografi 1454-1835. Tirana, 1997.

17 NOLI, Fan Stylian. George Castrioti Scanderbeg (1405-1468). Boston: International Universities Press, 1947.
} 


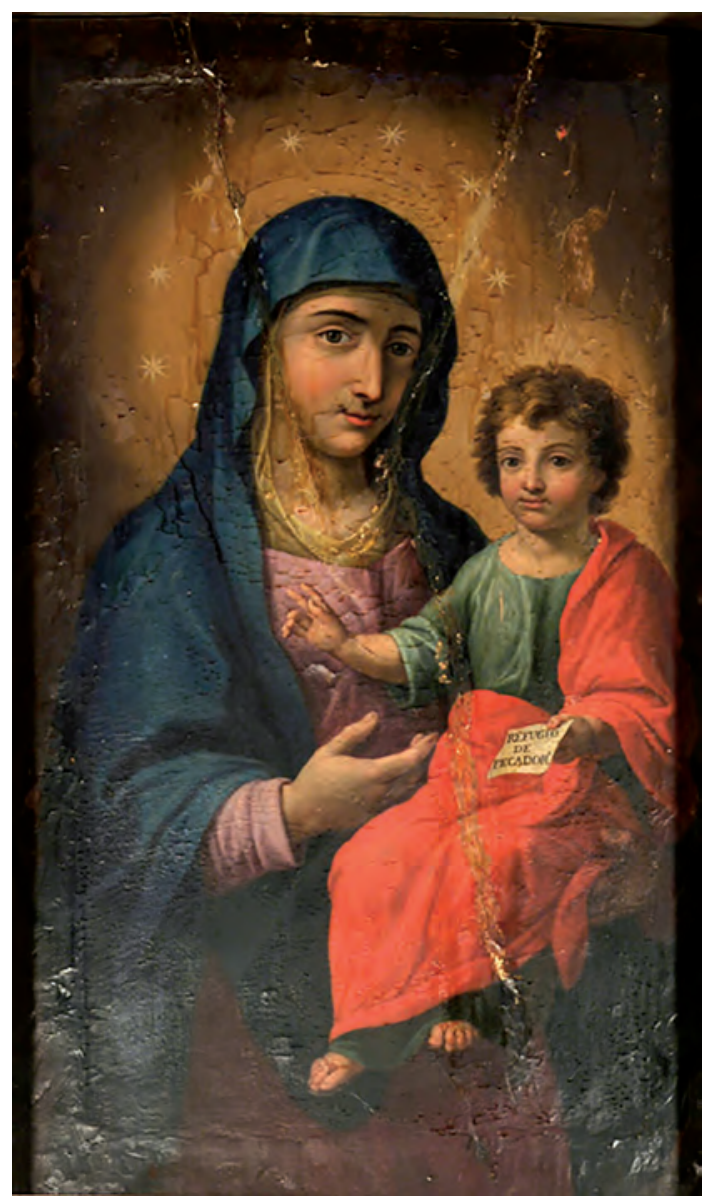

Fig. 4. Icono de Ntra. Sra. del Refugio de Pecadores en el Monasterio de la Santísima Trinidad de Valencia.

1965) historiador, periodista, teólogo y obispo fundador de la iglesia ortodoxa albanesa, a partir de su disertación doctoral en la Universidad de Boston (1945). Ha sido objeto de múltiples reediciones en inglés y albanés y recientemente contestada por la polémica biografía critica, publicada en alemán, por el historiador suizo Oliver Jens Schmitt, que ha pretendido una sustancial revisión de su figura y contexto provocando fuertes reacciones. ${ }^{18}$

La historia de Scanderbeg gira en torno a una compleja y confusa sucesión de batallas, guerras de guerrilla y oscuras gestiones diplomáticas difíciles de interpretar y su identidad histórica ha sido manipulada de tantas maneras que induce a la controversia. Incluso el contexto histórico en el que se movió durante el siglo XV, centrado en las regiones que contornean al mar Adriático, constituye una complejísima trama de intereses que implica la conflictiva competencia entre Venecia y el Reino de Nápoles por la hegemonía de esta zona, la potencia expansiva de los turcos otomanos y la participación interesada de Hungría y el Papado. También influyeron en el desarrollo de los acontecimientos las cambiantes relaciones entre musulmanes, católicos y ortodoxos, con proteicos enfrentamientos y alianzas en un territorio donde ciudades, clanes y pequeños señoríos se enfrentaban unos con otros sin querer unirse ni siquiera para defenderse del enemigo común. Una época y contexto en que las fuentes son escasas e inseguras.

Los Castrioto eran una familia terrateniente. Su padre Gjon (Juan) Castrioto ( $\$ 1437)$ poseía un señorío en Epiro y estaba casado con Voisava. ${ }^{19}$ Tuvo varios hijos de los que conocemos a cuatro varones: Stanisto, Reposio, Constantino y Jorge (Scanderbeg) y cinco mujeres: Mara, Elena, Angelina, Vlajka y Mamica. Su resistencia a la acometida turca del sultán Bayaceto I en los Balcanes fue infructuosa, y a causa del contexto geopolítico de la época, tuvo que cambiar sus lealtades. Como vasallo de los otomanos se vio obligado a rendir tributo, a prestar servicios militares, y entregar algunos de sus hijos, bien como rehenes o reclutados según el sistema del devshirme. ${ }^{20}$ Aunque las fuentes difieren y son confusas, de Reposio se dice que fue monje en el Monte Athos y allí fue enterrado, mientras que los otros tres fueron conducidos en

${ }_{18}$ Oliver Jens Schmitt es profesor de Historia del Sudeste de Europa en la Universidad de Viena, y reputado académico de varias instituciones. Su extensa documentada biografía de Scanderbeg ha encontrado serias críticas y encendido un debate en Albania por determinadas afirmaciones, de las que se pueden derivar repercusiones políticas. Adrian Klosi (1957-2012), doctor en literatura alemana comparada por la Universidad de Innsbruck, escritor, especialista en albanología y activista social albanés, que tradujo este libro al albanés y fue acusado de traición, se suicidó en 2012. SCHMITT, Oliver Jens. Skanderbeg: Der neue Alexander auf dem Balkan. Regensburg: Pustet Friedrich KG, 2009.

19 Oliver Schmitt afirma que Voisaba Tribalda, la madre de Jorge Castriota-Scanderbeg, era serbia y quizá emparentada con la familia Brancovic, lo que ha provocado encendidas protestas de los albaneses, en el marco de las disputas entre historiadores y políticos de Albania, Serbia y Macedonia.

${ }^{20}$ El dev irme era un sistema de reclutamiento establecido por los otomanos a modo de tributo sobre las minorías cristianas de los Balcanes. Los niños eran enrolados antes de la adolescencia y educados como musulmanes en instituciones oficiales entrenándolos para formar parte de la administración del Imperio, en la que podían llegar a desempeñar altos cargos. Los que recibían adiestramiento militar eran destinados a formar parte de los cuerpos de jenízaros: una clase de soldados de elite leales solo al sultán. 
1415 a la corte otomana, donde Jorge Castrioto se debió convertir al islam y asistió a la escuela militar en el Enderun de Edirne.

Durante el reinado de Murat II (1421-1451) marcado por la larga guerra contra los cristianos balcánicos y los emiratos turcos de Anatolia, Jorge Castrioto destacó como jenízaro y por sus victorias recibió el título de Skender Bey (Skënderbeu, en albanés). También obtuvo del sultán varios feudos y gobernaciones en su tierra natal. Sin embargo, en 1443, cuando luchaba contra los cruzados húngaros de Janos Hunyadi (el papa Eugenio IV había proclamado una cruzada contra los turcos) durante la bataIla de Nish, desertó junto con su sobrino Hamza y 300 albaneses jenízaros. Consiguió apoderarse de Krujë (Croya) y desde su castillo estableció un dominio en los terrenos circundantes en el centro de Albania. Hizo pública apostasía de la fe musulmana, obligó a sus seguidores y súbditos a adoptar el cristianismo y proclamó que vengaría a su familia y a su país de la opresión turca, levantando su bandera con el águila bicéfala y desafiando a los turcos. A continuación, en 1444, convocó a varios clanes de la nobleza militar balcánica para promover y dirigir la insurrección contra los otomanos y establecer, con el apoyo de Venecia, una alianza militar, conocida en la historiografía como la Liga de Lezhë.

En adelante y durante muchos años, Scanderbeg aprovechando el terreno escabroso de aquellas tierras construyó fortalezas y bastiones en las montañas y se dedicó a hostigar a los otomanos para obligarles a dispersar sus fuerzas, manteniendo variables alianzas con los potentados locales y logrando con fuerzas reducidas algunas victorias relevantes que propagaron su fama por Europa. Pero la República de Venecia, que en un principio le había apoyado, comenzó a ver en su consolidación una amenaza para sus intereses en Albania y se convirtió en implacable enemiga dando lugar a un periodo de $\operatorname{conflictos}^{21}$ que de algún modo le incitó a intensificar sus relaciones con Alfonso V de Aragón (1416-1458) rey de Nápoles y principal rival de Venecia en el Adriático. Con el monarca aragonés estableció estrechos vínculos al firmar, el 26 de marzo de 1451, el Tratado de Gaeta por el que se sometía a vasallaje a cambio

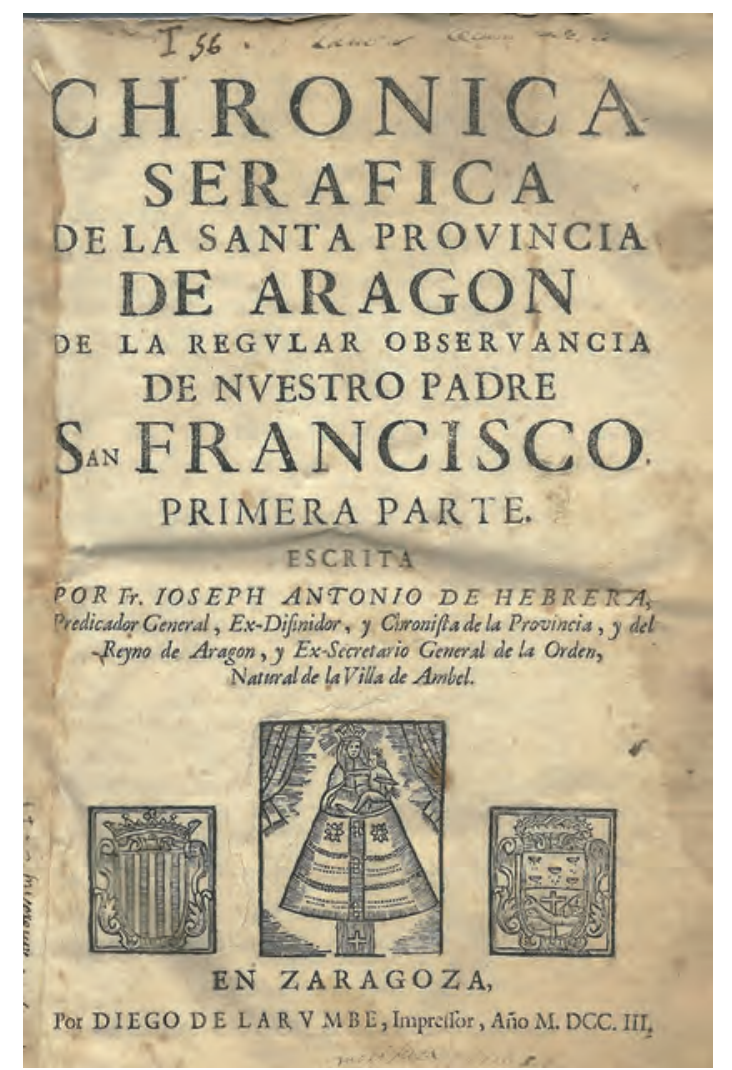

Fig. 5. Chronica real seráfica del reyno y santa provincia de Aragón de la regular observancia de nuestro padre san Francisco, considerada la serenissima inclita casa reynante en Aragón Mallorca, Sicilia y Nápoles con distintos solios, fray Joseph Antonio de Hebrera, Diego de Larumbe, Zaragoza, 1705.

de ayuda financiera, tropas y equipo militar para su guerra contra los otomanos. En este acuerdo se le ofrecía además refugio en Nápoles, junto con su familia, en caso de necesidad. ${ }^{22}$

Un mes después del tratado, Scanderbeg se alió con Gjergj Arianiti Komneni (1376-1470), enérgico combatiente contra los turcos y jefe de una las familias nobles albanesas más influyentes. El 21 de abril de 1451, en presencia de los miembros de la Liga de Lehzë, se casó con su hija mayor Donica Arianiti, ${ }^{23}$ en el monasterio ortodoxo de Ardenica.

\footnotetext{
21 En junio de 1450 un ejército otomano de 150.000 hombres a las órdenes de Murat II había sitiado Krujë, pero no pudo tomar el castillo. Murat murió en el invierno de 1450-1451 y le sucedió en el sultanato su hijo Mehmet II.

22 Además de los reyes de Nápoles, Alfonso y Ferrante, y los papas Pio II, Nicolás V, Calixto III y Pablo II, otro de los aliados del Castriota fue Vlad III Draculea, príncipe de Valaquia.

${ }^{23}$ Sus padres, Gjergj Arianiti y su primera esposa María Muzaka, pertenecían ambos a linajes nobles con dominios señoriales. Donika había nacido en 1428 en el castillo de Kaninë (Vlorë) en el momento de su boda tenía 23 años; el novio frisaba los 46. Schmitt la llama Andrónica Arianiti: SCHMITT, Oliver Jens (véase nota 19), p. 45.
} 


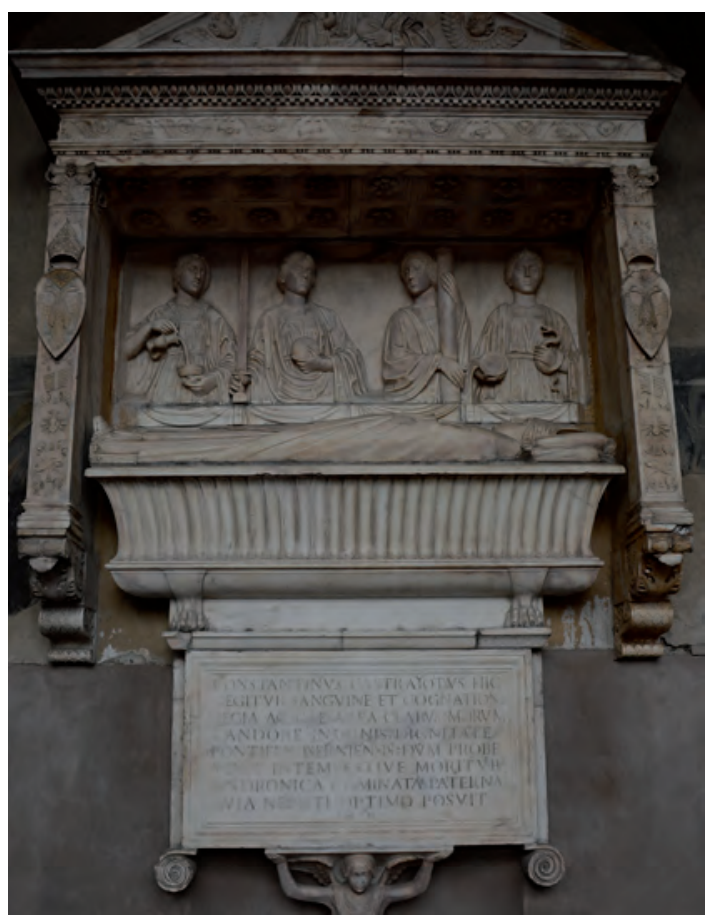

Fig. 6. Sepulcro del obispo Constantino Castriota en Santa Maria la Nova, Nápoles.

La boda fue suntuosa, duró tres días, y su recuerdo ha permanecido en poemas y canciones del folklore albanés. En 1455, nació su único hijo varón, Juan (Gjon) Castrioto (1455-1505). Scanderbeg continuó construyendo fortalezas en lugares estratégicos y organizó una defensa móvil utilizando las escarpadas montañas del país con una táctica de guerrillas que dispersaba las fuerzas turcas y retrasaba la conquista. La rebelión de Scanderbeg no fue un levantamiento general de todos los albaneses, ${ }^{24}$ pero sus veinticinco años de resistencia contra el imperialismo otomano permitieron proteger la península italiana de la amenaza de invasión turca.

En 1458, aunque seguía luchando en Albania contra los turcos, ${ }^{25}$ Scanderbeg, a causa de la muerte de rey Alfonso, tuvo que acudir en ayuda de su sucesor Ferrante (1423-1494), hijo bastardo del monarca y de la dama valenciana Giraldona Carlino, ${ }^{26}$ para recuperar y mantener su reino de Nápoles frente a la rebelión de la nobleza local; revueltas que se repitieron en 1460. Los soldados albaneses ayudaron a Ferrante a derrotar a sus oponentes y el rey agradeció a Scanderbeg estas intervenciones prometiéndole posesiones en Apulia. A partir de 1462, Scanderbeg tuvo que combatir de nuevo en Albania y en 1466 y 1467 enfrentar sendas invasiones comandadas por el propio sultán Mehmet $1{ }^{27}$ que volvió a sitiar Krujë. Durante estos feroces conflictos Scanderbeg enfermó de malaria en Lezhë, ciudad controlada por los venecianos, y murió el 17 de enero de 1468, a los 62 años. Tras tantos años de guerras la destrucción fue inmensa y el país quedó terriblemente devastado, pero la resistencia albanesa continuó aun durante una decena de años. ${ }^{28}$

En 1468, durante el cuarto sitio de Krujë, los otomanos consiguieron tomar la ciudad, y Donica con el hijo de Scanderbeg, entonces muy joven debió abandonar el castillo, acompañada por otros familiares parientes de su esposo, y refugiarse en Italia. El hijo de Scanderbeg, con otros familiares y algunos seguidores, fue acogido por el rey Ferrante y admitido entre la nobleza local. Se amparó en el castillo de Monte Sant'Angelo, que Ferrante había asignado al padre junto con San Giovanni Rotondo, ambos en el Gargano, formando un feudo, muy importante, prestigioso por su vinculación al famoso Santuario del Arcángel San Miguel y rico en privilegios. ${ }^{29}$ Años más tarde, el hijo de Scanderbeg inten-

\footnotetext{
${ }^{24}$ Sus acciones se realizaron desde el centro de Albania, pues en el sur señoreaban los turcos y el norte era una zona de influencia veneciana. Otros intereses enfrentaban a los habitantes de las montañas con las ciudades de las Ilanuras.

${ }^{25}$ El 29 de mayo de 1453 Mehmet II Fatih Sultán (1432-1481) conquistó Constantinopla y puso fin al Imperio bizantino. Dos años después, en 1455 Jorge Castrioto Skanderbeg, que sitiaba Berat, traicionado por su sobrino Hamza Castrioto, fue derrotado por el sultán. En 1457, un ejército otomano de 80.000 soldados invadió Albania para acabar con la resistencia. Skanderbeg atacó a los otomanos en septiembre, entre Lezhë y Krujë, y los derrotó. No obstante, tras la muerte de Alfonso el Magnánimo, en 1458, sus sueños de un imperio aragonés mediterráneo, en el que Scanderbeg podía ser un factor, desaparecieron.

${ }^{26}$ DE SOSA, Gerónimo. Noticia de la Gran Casa de los Marqueses de Villafranca..., Nápoles, 1676, pp. 121-123 y 174-175.

27 De nuevo en Albania, en 1464 Scanderbeg derrotó a Ballaban Badera, un albanés al servicio de los turcos que había capturado y enviado a Estambul a muchos capitanes albaneses. En 1466 un ejército dirigido por el propio Mehmet II entró en Albania y sitió Krujë construyendo un campamento fijo (Elbasan), pero gracias al apoyo marítimo de los napolitanos, Scanderbeg consiguió romper el asedio. A finales de 1467 Mehmet II, preparó otro gran ejército y volvió a sitiar Krujë.

${ }_{28}$ Un ejército mandado por Leke Dukagjini (1410-1481) que había luchado bajo el mando de Scanderbeg derrotó a los otomanos en Shkodra, antigua capital de la región, y dirigió la resistencia albanesa durante varios años.

${ }^{29}$ En 1494 Monte Sant'Angelo y San Giovanni Redondo serian devueltos a la corona a cambio de Soleto y el ducado de San Pietro en Galatina en el Salento.
} 
taría desde la costa meridional albanesa recuperar lo perdido. Establecido al principio en el castillo de Himarë, una fortaleza natural del distrito de Vlorë, luchó contra los otomanos, propiciando un levantamiento local con la ayuda de la flota napolitana. ${ }^{30}$ Juan Castrioto continuó la resistencia entre 1481 y 1484, pero le fue imposible restablecer su principado y liberar Albania del yugo otomano. ${ }^{31}$ Después, la resistencia albanesa continuó esporádicamente hasta principios del siglo XVI. ${ }^{32}$

Juan Castrioto que se había casado con Jerina (Irene) Brancovic, hija del déspota serbio Lazar Brancovic y Elena Paleologo, tuvo varios hijos: María, Jorge, que fracasó combatiendo a los turcos (†1540), Constantino (obispo de Isernia, fallecido en 1500), y Ferrante, que heredó el ducado y las demás propiedades. Ferrante falleció en 1561, dejando de su matrimonio con Adriana Acquaviva d'Aragona solamente una hija legitima, Irene, en quien se acabó el linaje directo de Scanderbeg. ${ }^{33}$

También, Donica, la esposa de Scanderbeg, invitada por el rey Ferrante se refugió en Italia, acompañada por su hija Vaisaba y por otros familiares descendientes de su cuñado Stanisto por los que había manifestado gran interés y afecto. ${ }^{34}$ Unos meses después de la muerte del marido, el 23 de mayo de 1468, llegó a Nápoles, donde fue acogida por el monarca, se le asignó una residencia digna, una pensión y se la trató con el mayor respeto. Pero su situación aun mejoró, sobre todo por su relación con Juana III de Nápoles, ${ }^{35}$ segunda esposa

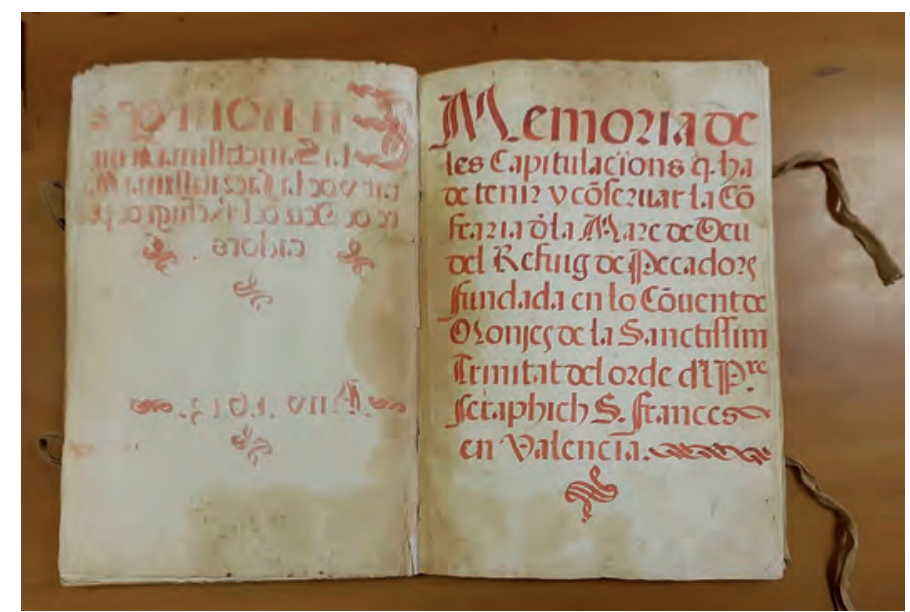

Fig. 7. Memoria de les Capitulacïons q ha de tenir y côservar la Côfraria d la Mare de Deu del Refugi de Pecadors fundada en lo Côvent d Monjes de la Sanctissim Trinitat..., Arxiu del Regne de Valéncia, Varia, libros, nº 918.

de Ferrante (1476) quien era hermana de Fernando el Católico. El rey escogió a Donica como dama de compañía de su joven esposa y por ello ahora fue alojada en el Castell Nuovo, en dependencias próximas a la cámara de la nueva reina. ${ }^{36}$ La reina Juana demostró siempre grandes aptitudes políticas y de gobierno. En 1481, cuando los turcos ocu-

${ }^{30}$ El hijo de Scanderbeg logró vencer a un ejército turco comandado por Solimán Alibeg, a quien hizo prisionero. GUALDO, Lucia et al., Gli Umanisti e la guerra otrantina: testi dei secoli XV e XVI. Bari: Edicioni Dedalo, 1982, p. 97.

31 A lo largo de 1480, las tropas de Mehmet II conquistaron Albania que además invadieron Italia y saquearon Otranto, masacrando a sus habitantes. El sultán murió en mayo de 1481 y en septiembre Ferrante de Nápoles logró liberar la ciudad mártir con la ayuda del rey de Hungría Matías Corvino, hijo de Juan Hunyadi, y de la flota pontificia de Sixto IV. Esta victoria y la resistencia de Juan Castrioto le decidieron a planear una ofensiva en Albania, que desanimase a los otomanos de cualquier otro intento de atacar a su reino napolitano, proyecto que finalmente abandonó al perder el apoyo de la flota pontificia, regresando a Italia en 1484

32 Todavía, en febrero de 1501, el hijo mayor de Juan, Jorge Castrioto, nieto de Scanderbeg, en una expedición a Albania, apoyada por Venecia, intentó un levantamiento local en Lezhë que no tuvo éxito.

33 Irene Castriota, que falleció en 1565, se había casado en 1539 con Pietro Antonio Sanseverino d'Aragona, por lo que el ducado de San Pietro in Galantina y los demás títulos y feudos pasaron a este ilustre linaje napolitano. El apellido Castrioto continuó sin embargo a través de otros descendientes, los numerosos hijos ilegítimos del duque Ferrante: Pardo, Achile, Federico, Alfonso, Cesare, etc. PANZERA Giovanni. Quei bastardi dei Castriota Scanderbeg (inédito); SALES, Agustín, 1761 (véase nota 2), p. 120.

34 Donica que había recibido protección y ayuda de Stanisto en Albania siempre se mostró agradecida en sus descendientes. En Nápoles le acompañaba su sobrino Brano (Bernardo) con su esposa Mará Zardarí, que fueron padres de Isabella, Giovanni, Giovanna, Alfonso y Ferrante. Con el tiempo los varones ofrecieron sus servicios en la milicia y las mujeres fueron damas de la corte.

35 En 1476, a los 52 años, el rey Ferrante de Nápoles se había casado en segundas nupcias, con su prima Juana (1456-1517), infanta de Aragón, hija de Juan II y su segunda esposa Juana Enríquez, y por tanto hermana menor del rey Fernando el Católico. La ceremonia oficiada por el cardenal Rodrigo de Borja culminó con la coronación de Juana III, como reina de Nápoles.

36 "Stanze delle dame della Regina Madre.-Sull'appartamento della Regina, al secondo piano, domoravano le dame. Un scala a chiocciola, evidentemente la stessa che saliva dalla corte all'appartamento, vi accedeva. Ivi era una sala da pranzo. Nelle altre camere alloggiavano "madama" Andronica Araneti Scanderbech, una "madama Porfida", non meglio nota...", FILANGIERI, Riccardo. "Rassegna critica delle fonti per la storia di Castel Nuovo", Archivio Storico per le Province Napoletane, vol. 63, Napoli, 1938, p. 290. Madama Porfida bien pudo ser Porfida Musachi, pariente de Donica por la línea materna. 


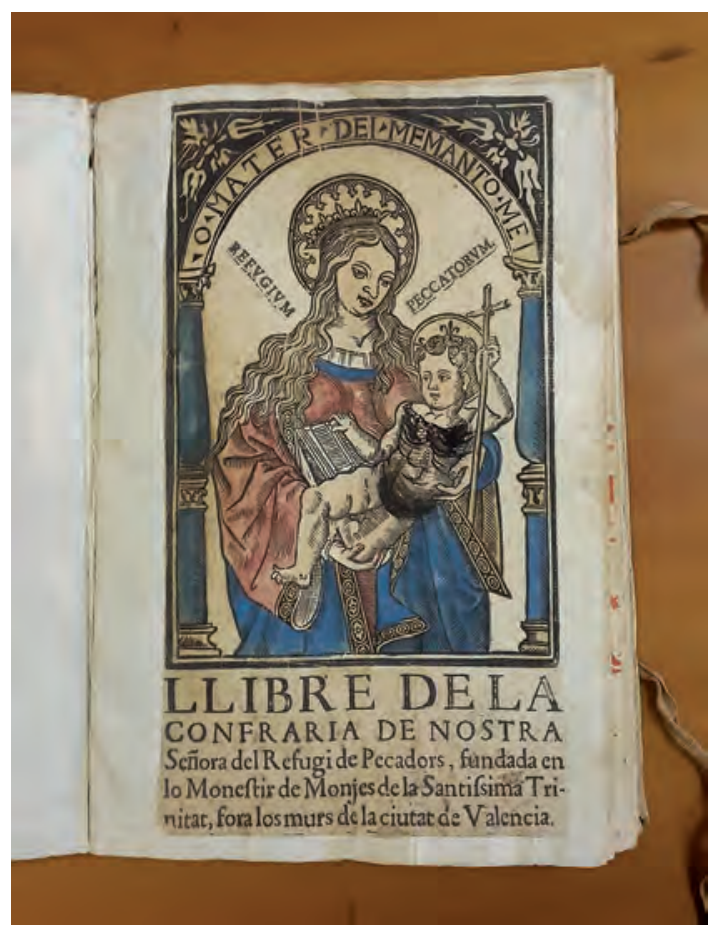

Fig. 8. Grabado de Ntra. Sra. del Refugio en el Libro de la cofradía homónima, Arxiu del Regne de Valéncia, Varia, libros, no 918.

paron Otranto, el rey Ferrante, centrado en la defensa de las costas del reino y en repeler la agresión otomana, la nombró lugarteniente del reino; una función, que desempeñó con tan notable eficacia, que le fue requerida también, tanto en el reino de
Nápoles por sus sucesores Alfonso II, Ferrandino y Fadrique $\mathrm{III} ;{ }^{37}$ como por el propio Fernando el Católico en relación al de Valencia, como veremos. Entre la reina Juana y Donica, que también debió gozar de similares aptitudes y supo desempeñarse con energía y decisión en su agitada biografía, se suscitó una relación que se mantuvo sólida y afectuosa, a pesar de la diferencia de edad. ${ }^{38}$ En 1479 , Juana había dado a luz una hija de Ferrante a la que se impuso su mismo nombre, y Donica fue nombrada tutora de su hija, ${ }^{39}$ mientras que ejercía de nodriza Maria Zardari, joven esposa de su sobrino Brano/ Bernay Castriota, conde de Cupertino. ${ }^{40}$

La buena situación de Donica y sus parientes, que acabaron constituyendo un poderoso clan en la corte napolitana, se mantuvo durante los sucesivos $\mathrm{y}$ breves reinados $\mathrm{y}$ en medio de las agitadas condiciones del reino. En mayo 1494 fue coronado Alfonso II (1448-1495) hijo de la primera mujer de Ferrando, Isabela de Chiaromonte. El nuevo monarca mantuvo a la reina viuda Juana III en su cargo de lugarteniente general del reino. ${ }^{41}$ Sin embargo, al poco, en 1495, el rey Alfonso se vio obligado a abdicar ante la amenaza de las tropas francesas de Carlos VIII, propiciando la ascensión al trono del joven Fernando II, que fue llamado Ferrandito. Era hijo suyo y de Hipolita María Sforza, y nieto pues del primer vinculo de Ferrante I. Tenía 27 años y sería desposado con su tía paterna, la princesa de 18 años, Giovanna di Napoli (Juana IV) ${ }^{42}$ la hija de la reina Juana III. ${ }^{43}$ La ciudad era asediada por las tropas francesas y Ferrando II se vio obligado a fugarse para organizar una liga de barones italianos, que, con la ayuda de tropas españolas al mando de Gonzalo Fernández de Córdoba, el Gran Capitán,

\footnotetext{
37 "In questa occasione fu a tutti manifestò in quanta stima, per il suo accorgimento, tenesse quel re, già maturo di anni e di consiglio, la sua giovane sposa. Volendo egli dedicarsi interamente alla difesa maríttima, nominò Giovanna luogotenete generale del regno" SCANDONE, Adele. "Le triste reyne di Napoli Giovanni III a Giovanna IV d'Aragona", ASPN, n XIV, Napoli, 1928 , p. 130.

${ }^{38}$ De la confianza de la que gozaba Donica respecto a Juana III y su ascendiente sobre la reina (citando también a Brano Castrioto), da testimonio en 1496, el rey Fadrique (Federico): "riconoscente, ringraciava il legato pontificio, il conte Vernay e la contessa Scanderbech, que avevano perorato preso Giovanna a suo favore", SCANDONE, Adele. "Le triste reyne di Napoli Giovanni III a Giovanna IV d'Aragona", ASPN, n XV, Napoli, 1929, p. 153.

39 El 20 de abril de 1479 nació Giovanna d'Aragona, a quien nombraremos Juana IV (1479-1496), porque llegaría también a ser reina de Nápoles, aunque fugazmente, por su matrimonio con Fernando II (1469-1496) llamado Ferrandito.

40 "Sull'appartemento del Re, Alfonso I aveva construito alcune stanze, (...) Sullo stesso piano vi erano varie altre camere con un corridoio. Alcune di esse erano tenute da Bernay Castriota Conte di Copertino, albanese, cortigiano della Regina madre, e da la moglie di lui Donna Maria, che era stata la nutrice dell'Infante Giovanna, che fu poi la moglie di Ferrandino" FILANGIERI, Riccardo, 1938 (véase nota 36), p. 296.

41 SCANDONE, Adele, 1928 (véase nota 37), p. 136 y sigs.

42 "L'unione di quei due giovani, nei quali batteva lo stesso sangue, di quei superstiti dei reali aragonesi di Napoli, fu del popolo appresa con rinnovata onda di tenerezza, e con lieto augurio", CROCE, Benedetto. Storie e leggende naopletane. Bari: Laterza, 1959, p. 143-163.

${ }^{43}$ El matrimonio, organizado por la madre Juana III, fue concertado el 28 de febrero de 1496, una vez obtenida la dispensa papal, convirtiendo a Ferrandito en sobrino político del poderoso soberano español. La reina madre asumió otra vez la lugartenencia: "Ferrandino, profittando si quell'aura popolare, constituì di nuovo la Regina suo lougotenete generale" SCANDONE, Adele, 1928 (véase nota 37), p. 148 y sigs.
} 
logró vencer a los franceses en 1496. Desgraciadamente, el 7 de septiembre del mismo año, Ferrante II (1469-1496) falleció de malaria a los 29 sin haber tenido tiempo de engendrar descendencia, dejando otra reina viuda. Fue nombrado heredero el duque de Calabria, su tío Fadrique (1452-1504). El rey Fadrique III de Aragón y Chiaramonte, era hermano de Alfonso II, descendiente también del primer vínculo de Ferrante I, pero con su ascenso al trono, y sobre todo por su matrimonio con Isabella del Balzo, la situación cambió para las dos reinas viudas y por ende para su protegida Donica Scanderberga y su familia albanesa.

Durante el reinado de Federico/Fadrique III, Nápoles fue invadido por Luis XII de Francia. ${ }^{44}$ El monarca solicitó ayuda en vano a su pariente Fernando el Católico, pero este que se creía con más derechos que su sobrino segundo al trono napolitano y lejos de dársela se entendió con el monarca francés. Estas ladinas negociaciones para derrocar a Federico, y repartirse el reino de Nápoles conducirían al tratado de Granada (1500). ${ }^{45}$ Durante el desarrollo de estas maquinaciones, Fernando el Católico reclamó la presencia de su hermana Juana III, que se embarcó el 7 de septiembre de 1499, con el renuente permiso de su hijastro y el pretexto de consolar a su hermano y cuñada, que acababan de perder dos hijos: el príncipe heredero Juan y la infanta Isabel, casada con el rey de Portugal. Según algunos autores, las dos reinas viudas, Juana III y su hija Juana IV, hermana y sobrina suyas, marcharon juntas hacia España, acompañadas por Gonzalo Fernández de Córdoba y algunos prelados. ${ }^{46}$ Sin embargo, fuentes más seguras indican que las dos reinas no

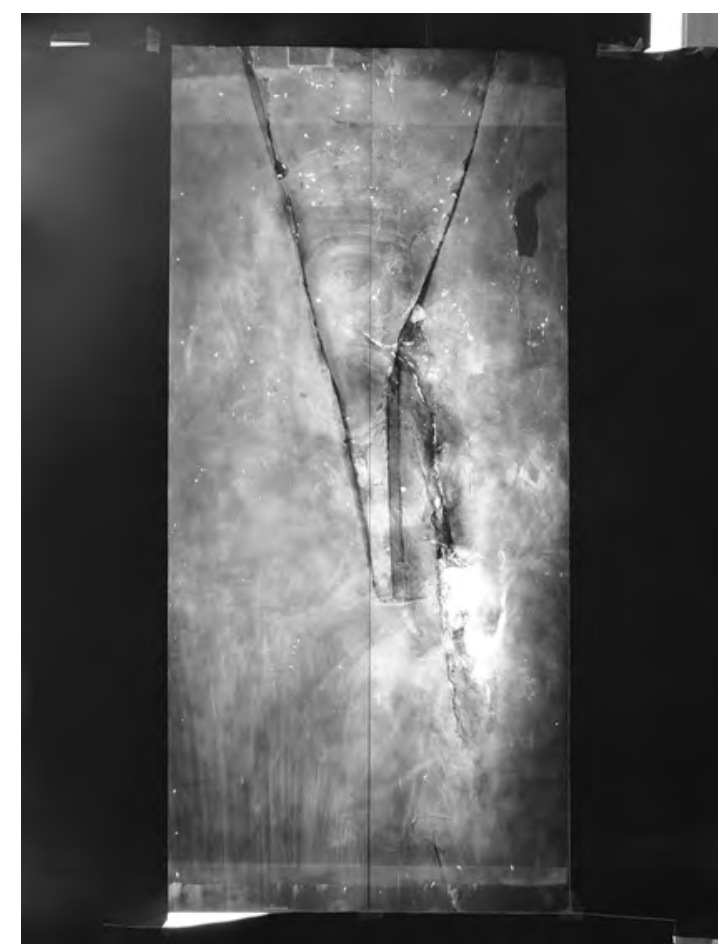

Fig. 9. Placa radiográfica del icono de Ntra. Sra. del Refugio, Pilar Ineba, 1999.

se fueron al mismo tiempo, ${ }^{47}$ pues parece que Juana IV había permanecido en Nápoles al cuidado de Donica y bajo la protección de su sobrino Brano, cortesano y hombre de confianza de Juana III. ${ }^{48}$ Dos años más tarde, el 2 de agosto de 1501, ante el pe-

44 Luis XII de Francia (1462-1515) primo y heredero de Carlos VIII, reinó de 1498 a 1515.

45 ZURITA, Jerónimo. Historia del rey D. Fernando el Católico. De las empresas y ligas de Italia 1580, vol. I, libro III. cap. XL: "De la concordia que se propuso por parte del rey, del repartimiento del reino de Nápoles".

46 Según nos cuentan los cronistas, en 1499 marcharon a España "las Reynas de Nápoles madre e fija, hermana y sobrina de Rey Don Fernando, y con ella el Gran Capitán Gonzalo Fernández de Córdoba (...) e quedo en Aragón la Reyna moza en un lugar cercano a Valencia, é la madre vino a Granada...", GENOVES, Vicente. La triste reina de Nápoles, hermana del rey Católico. Madrid: Editora Nacional, 1947, p. 44.

47 Zurita, al referirse a este viaje, no cita a la joven Juana entre los acompañantes de su madre: "Era venida por este mismo tiempo la reina de Nápoles hermana del rey a España: y desembarcó en Almería: e iba con ella el cardenal don Luis de Aragón, nieto del rey don Fernando su marido: y el rey la fue a recibir a Guadix: y la acompañó hasta Granada: donde entró en el mes de octubre: y mediado el de noviembre, partieron de Granada, para ir a tener el invierno a Sevilla: y se detuvieron parte de él en Alcalá la Real, Baena, Écija, y Carmona." ZURITA, Jerónimo, 1580 (véase nota 45), Vol. I, libro III. cap. XLI: “De la ida de la reina de Nápoles a Granada; y que el rey y la reina enviaron a la princesa Margarita su nuera a Flandes".

48 Por el contrario A. Scandone dice que tras cenar a bordo con Juana III: "sbarcati poi il re, la regina sua sposa e Giovanna IV, furono verso la mezzanotte salpate le ancore; e súbito si fece vela verso occidente" SCANDONE, Adele, 1929 (véase nota 38 ) p. 169-170; El legado veneciano en Nápoles, Francesco Morosini, escribe que Juana IV quedó bajo la protección de Donica y su sobrino el conde de Cupertino:"la reina fiola rimasta a Napoli, di anni venti, fo moglie di re Ferrandino: honestissima, et ogn suo atto fa con prudentia; ha con lei la moglie fo dil signor Scandarbecho vecchio, molto amicha di la Signoria nostra (....) item il conte di Convertino è a custodia di dita reina, è homo degno" (noticia generosamente aportada, como otras, por el historiador y genealogista Giovanni Panzera). Por otro lado, todavía en el año 1500, Donica se ocupaba del adorno de la suntuosa sepultura de su nieto, el obispo Constantino, en el claustro de la iglesia napolitana de Santa María la Nuova, cuya inscripción está fechada en el año 1500: "CONSTANTINUS CASTRAYOTUS HIC TEGITUR SANGUINE ET COGNATIONE REGIA AC CAESAREA CLARVS: MO-RVM CANDORE INSIGNIS: DIGNITATE PONTIFEX AESERNIENSIS: DUM PROBE VIVIT INTEMPESTIVE MORITVR ANDRONICA COMINATA PATERNA AVIA NEPOTE OPTIMO POSUIT. MD". 


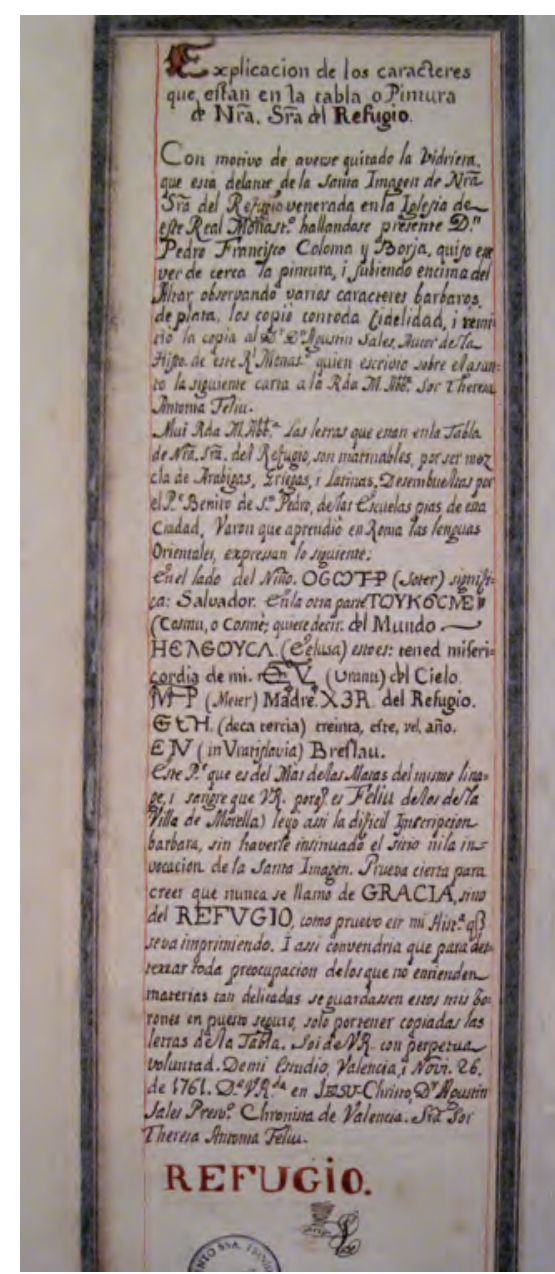

Fig. 10. Anotaciones sobre Ntra. Sra. del Refugio en el Libro Mayor de Títulos, 1761, Archivo del Monasterio de la Santísima Trinidad de Valencia.

ligro de la inminente toma de la ciudad por las tropas francesas, Juana IV zarpó rumbo a Sicilia, ${ }^{49}$ acompañada por Donica, Brano y algunos familia- res; pues si la albanesa era amiga y confidente de la madre, también había ejercido como una segunda madre de la hija.

Federico III no pudo hacer frente a ambos contendientes. Mientras los aragoneses, al mando del Gran Capitán, ocupaban Apulia y Calabria, las tropas francesas, comandadas por Ebérard Stuart D'Aubigny, tomaron Capua en julio de 1501, y entraron en Nápoles el 19 de agosto, pocos días después de la partida de Juana IV. Federico se entregó a los franceses a cambio de amnistía para sus súbditos, fue depuesto con el refrendo del papa Alejandro VI, que aprobó la partición del reino. Federico partió con su séquito hacia Francia. En noviembre se entrevistó con Luis XII en Lyon, donde renunció formalmente al reino de Nápoles a cambio del condado de Maine y una cuantiosa renta anual; falleció en Tours (1504)..$^{50}$ Con el arresto del rey Federico y la ocupación de la capital por los franceses, la situación de Juana IV, y sus acompañantes se volvió incómoda $^{51}$ y obtenido el permiso del rey Católico, en 1502, el grupo se embarcó, y llegó a Valencia y probablemente fue acogido en el Palau Reial, donde la reina Juana III, que en 1501 había sido nombrada por su hermano lugarteniente general en el Reino de Valencia, había creado una pequeña corte.

Una relación diplomática refleja en 1505 al grupo reunido por entonces en Valencia. Quedó recogida en los informes de los embajadores ingleses, Francis Marsin, James Baybroke y John Stile, enviados por Enrique VII a Juana III para tratar de un posible matrimonio del rey, entonces viudo, con su hija Juana:

Pleaseth your Grace, at our coming to the city of Valencia, the which was in the XXII day of June in the evening, at which time the Queens of Naples both the old and the young, sojourned and kept their households together jointly in the King's palace, that is a little without the said city of Valencia, the which palace is called the Reyalls (...) Where at the hour and

49 La joven Juana salió de Nápoles el 2 de agosto de 1501, llegando a Sicilia de donde partió hacia las costas españolas el 16 de marzo de 1502, arribando a Valencia en el mes de julio. Archivio di Stato di Napoli, Curiae Summariae, vol. 26, fol. 152 (noticia aportada por el historiador y genealogista Giovanni Panzera).

50 "Le roi Frédéric convint avec d'Aubigny de le mettre paisiblement en possession de tout ce qui lui restait encore dans la partie de son royaume qui était échue à la France, se reservant seulment pendant six moins, l'île d'Ischia. Il se rendit dans cette île, où arriva bientôt après la flotte française, commandé par Philippe de Ravestein, dernier de cette branche à la maison de Clèves. Ce seigneiur lui accorda un sauf-conduit pour se render en France, et se jeter entre le bras de Louis XII. Sa confiance ne fut pas trompée: le roi lui accorda le duché d'Anjou et 30.000 ducats de rente. A condition quíl ne sortît pas du royaume". SCHOELL, Samson-Frédéric. Cours d'histoire des états européen. Depuis le Bouleversement de l'Empire Romain d'Occident jusq'en 1789. Paris/Berlin, 1831, vol. 16, p. 116-117.

${ }^{51}$ La joven reina utilizó las galeras españolas que estaban atracadas en Sorrento, feudo de su madre: "Mal sicura, cosi da ogni lato, Giovanna IV dové alla fine provvedere alla sua sicureza personale. Quando i Francesi entrarono in Napoli e Federico si ritirò ad Ischia, essa, il 3 agosto 1501 saliva sulle galee dell'ammiraglio Villamari, che salpavano, poco dipoi, per la Sicilia. La giovane Regina sbarcó a Palermo, ove si fermó quasi un anno, continuando a governare le terre sue e quelle della madre. La quale essa raggiunse in Ispagna, ove Giovanna IV aveva già presa dimora nel luglio 1502". SCANDONE, Adele, ASNP, $n^{\circ}$ XV. Napoli, 1929 (véase nota 38), p. 187. 
time appointed we came unto the said palace (...). Both the said queens were clothed in black cloth and also in black kerchoes as mourners, and in like case were all they waited on the said queens. On the right hand of the Queens in the window stood an ancient duke in a long beard, whose name is the duke Fernandin of Naples, and two of his sons, and other knights and gentlemen to the number of twenty persons or thereabouts, and to the left hand of the queens there sat the duchess, the wife of the said Fernandin, and duchess of the parties of Greece and the Marchesa de Chara, the Countesa de Tortona, and the Countessa de Montorio, and Donia Maria de Enrykes, the old queen's niece, and three daughters of the duke Fernandines, and other ladies and gentlewomen to the number of xviii or xx persons..$^{52}$

Desde luego en este texto se describe a un grupo muy numeroso de damas y caballeros, pero, junto a ambas reinas, los embajadores enumeran solamente a unos pocos. Además de Juana Enríquez, sobrina de la reina Juana III por la línea materna, destacan ante todo a los Castriota, conscientes de su relevante influencia. El anciano duque de Ferrandina podría ser Brano o Bernardo Castriota, sobrino de Scanderberg y cabeza de la línea de los Castriota Branai, que aparece con dos de sus hijos (quizá Giovanni que heredaría el ducado y Alfonso) y tres de sus hijas, $^{53}$ además de su esposa la duquesa, (se trata de María Zardai, la nodriza de Juana IV, sobrina política de Donica) a la que se señala como "duchess of the parties of Greece". Sin embargo, Donica, que en las crónicas napolitanas de su tiempo era denominada con el apelativo la Scanderberga, la Scannabelecca o simplemente la Greca, no aparece en este elenco quizá porque habría fallecido recientemente, como apunta Giovanni Panzera en su inédito, afectada por la trágica muerte del joven Alonso Castrioto. No obstante, gracias a este escrito vemos que al menos puede asegurarse la presencia en Valencia de varios familiares de Donica acompañando en posición muy relevante a las reinas napolitanas en el Palau Reial.

Pero existe además otro documento que indicaría la presencia de Donica en Valencia y su probable muerte y entierro en la cercana iglesia del Monasterio de la Trinidad, estrechamente vinculado al Palau

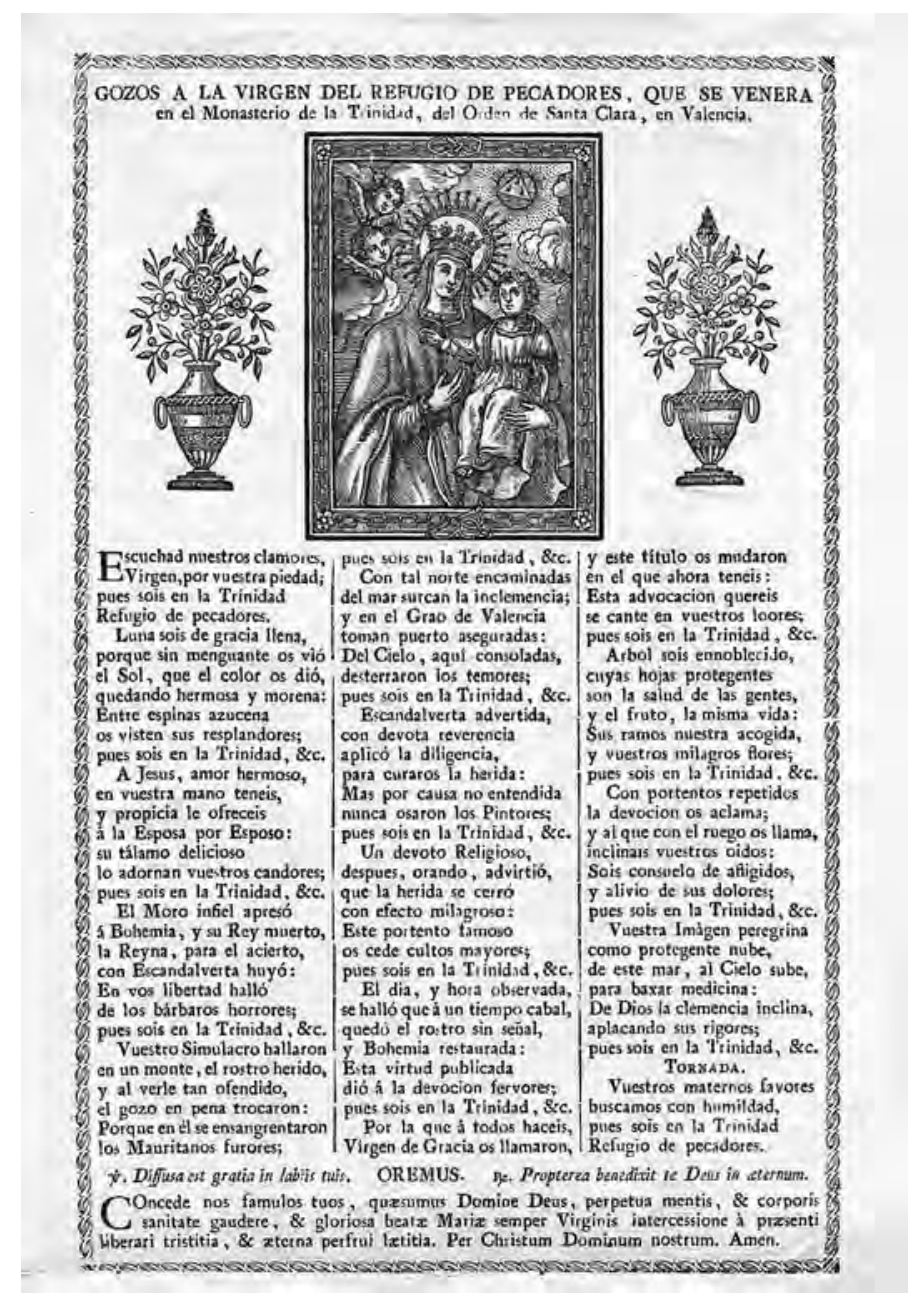

Fig. 11. Gozos a la Virgen del Refugio de Pecadores, que se venera en el Monasterio de la Trinidad, del orden de Santa Clara, en Valencia. Biblioteca Municipal Serrano Morales.

Reial y a la corte valenciana desde su fundación por la reina María de Castilla a mediados del siglo XV. El documento en cuestión recoge las últimas voluntades de la reina Juana III de Nápoles. Una primera versión de este testamento fue redactada en Valencia en noviembre de $1502,{ }^{54}$ aunque su muerte no

52 GAINDER, James (ed.). Historia regis Henrici septimi, a Bernardo Andrea Tholosate conscripta; necnon alia quedam ad eundem regem spectantia. London: Longman, Brown, Green, Longmans, and Roberts, 1858, p. 223-225.

${ }^{53}$ Brano/Branay/Bernardo Castriota tuvo de María Zarday tres hijos (Giovanni, Alfonso y Ferrante) y dos hijas: Isabella y Giovanna. Esta última fue íntima de las dos reinas y destacada beneficiaria de sus testamentos. Era de vida alegre y sus hermanos quisieron casarla con Guido Ferramosca, a pesar de que este ya había tenido relaciones con su hermana Isabela, pero ella no aceptó para permanecer con las reinas tras el regreso a Nápoles. Allí fundó San Diego del Ospedaletto, en la via Medina, cerca del Castel Nuovo, como refugio de nobles ancianos empobrecidos.

54 "En aquella ocasión se encontraba en Valencia junto a su hija Juana IV, huésped de su augusto hermano Fernando el Católico. En concreto, en noviembre las dos reinas se hallan en la compañía de su pariente el Duque de Calabria, último representante de la Casa de Aragón de Nápoles, retenido en Valencia en una prisión ambigua por el rey de España, que había privado al rey Federico, su padre del reino de Nápoles". PERUGINI, Carla; MARTínEZ GÁZQUEZ, José, 1992 (véase nota 4), p. 82. 
sobrevendría sino quince años más tarde, el 7 de enero de 1517, en Nápoles. Su hija Juana IV había llegado a Valencia pocos meses antes, en medio del verano, y ahora su madre, quizá impresionada por la caída de la capital en manos francesas, los profundos cambios que se avecinaban y "sic que multi intestati contra eorum animarum salutem decedunt et moriuntur", decide dictar su testamento instituyendo heredera a su hija Juana IV. Se trata de un documento extenso y prolijo, con numerosas y detalladas mandas y legados que incluyen a su entourage y entre esos beneficiados señala expresamente a muchos de los miembros de la prominente familia Castriota. Este testamento redactado en Valencia será ampliado, reformado y actualizado años después en su versión definitiva, dictada esta vez en Nápoles, dos días antes de su fallecimiento: "In lecto jacentem, infirman, corporis sanam tamen mentis et in recta sui loqucione et memoria pariter existente". ${ }^{55}$

Desgraciadamente el conocimiento exacto del texto auténtico resulta complicado; como todo en esta historia. El documento original, que se guardaba en el Archivio di Stato di Napoli, fue destruido durante los bombardeos aliados de 1943, en el curso de la segunda guerra mundial y solo lo conocemos a través de copias. En 1992, fue publicada una trascripción a partir de una copia conservada en la Real Academia de la Historia de Madrid: "entre los registros del secretario del emperador Carlos V, Juan González de Villasimpliz". La transcripción, a cargo de José Martínez Gázquez, está precedida por un interesante estudio de Carla Perugini, que ha podido compararla con la parte del testamento que publicó Emilio Nunziante en 1877, en su libro Un divorzio ai tempi di Leone $X$..., tomada del documento original antes de su destrucción. Sin embargo, al analizar la copia española Perugini indica que:

se trata de una copia realizada por diferentes amanuenses (...). Según queda constancia en la fe de erro- res y enmiendas registradas por el notario que da validez a la copia, él mismo ya ha encontrado numerosos añadidos e invalidaciones en el texto original (...) ¿cómo puede dar fe un documento en estas condiciones, en las que la manipulación de sus cláusulas es tan fácilmente disfrazable entre tantos copistas? ${ }^{56}$

De todos modos, el epígrafe que más nos interesa aquí, que debió ser añadido en Nápoles en la versión definitiva del testamento (1517), es la referente al destino de los restos de la leal amiga Donica, fallecida en Valencia. La reina Juana III era muy devota de la observancia franciscana y deseaba erigir en Nápoles un monasterio dedicado a Santa María de la Concepción y confiarlo a religiosas franciscanas clarisas como las de la Trinidad de Valencia. Pensaba incluso que tal fundación podría convertirse en el panteón de los reyes napolitanos de la casa de Aragón. Entre las numerosas disposiciones relativas a su erección y ornato la reina añade:

Item volimo et ordinamo che nella Ecclesia dela Conceptione seu de sancta Clara de dicto monasterio se edifiche una cappella con sepultura dove parera allí exquutori, et che lo corpo dela devota et amata Scannalibeccha sia portato de Valentia ad nostre spese, et sia honorevolmente sepulto nela sepultura de dicta cappella. (...) Et piu volimo che quella devota figura dela Virgine Maria quale sta in sancta Trinita che fo de donna Scannallibeccha se porta et pongase nela predicta capella in devotione et ornamento ipsius cappelle. ${ }^{57}$

Aunque estas disposiciones y otras muchas de su testamento no fueron cumplidas, el deseo de trasladar el cuerpo de su amiga y aquel icono de la Virgen que tanto apreciaba desde Valencia a Nápoles debió ser bastante conocido, pues la noticia fue recogida por fray Joseph Antonio de Hebrera, en su crónica de la provincia franciscana de Aragón, publicada en Zaragoza en $1705 . .^{58}$ Al tratar sobre la reina Juana III, recoge traducidas y adaptadas algunas cláusulas de su testamento, inclu-

\footnotetext{
55 Las reinas, tras asistir en la primavera de 1506 las suntuosas fiestas con motivo del segundo matrimonio de El Católico con Germana de Foix, volvieron a Nápoles, convertido en virreinato, en octubre de ese mismo año, acompañando al rey Fernando y su nueva esposa. Pero cuando en junio del año siguiente Fernando regresó a España, no se retiraron a la vida monástica, como era costumbre de las viudas reales, sino que vivieron la vida cortesana junto a sus damas, en compañía de sus parientes Isabel de Aragón, duquesa viuda de Nápoles y Beatriz la exreina de Hungría, frecuentando a nobles caballeros, y asiduamente a Giovanni Castrioto, duque de Ferrandina. Ambas se establecieron en el Castel Capuano y del esplendor de su corte se puede encontrar reflejo en la novela anónima Cuestion de amor, publicada en Valencia (1513) por Diego Gumiel, donde aparecen con seudónimo muchos personajes del entorno, incluidos los Castriota, y en otras obras literarias del mismo tono. Véase VIGIER, Françoise. Cuestion de amor, Introduction, edition et notes, Textes et documents du Centre de Recherche sur l'Espagne des XVIe y XVIIe siècles, $n^{\circ}$ IX. Presses Sorbonne nouvelle, París: 2006.

56 PERUGINI, Carla; MARTínEZ GÁZQUEZ, José (véase nota 4), 1992, p. 89.

57 PERUGINI, Carla; MARTínEZ GÁZQUEZ, José (véase nota 4), 1992, p. 105.

${ }^{58}$ HEBRERA, Joseph Antonio de. Chronica real seráfica del reyno y santa provincia de Aragón de la regular observancia de nuestro padre san Francisco, considerada la serenissima ínclita casa reynante en Aragón Mallorca, Sicilia y Nápoles con distintos solios, Zaragoza: Diego de Larumbe, 1705.
} 
yendo la relativa al traslado del cuerpo y el cuadro, refiriendo su veracidad a un historiador anterior que habría consultado el documento original: ${ }^{59}$

Item, queremos, y ordenamos que en la dicha Iglesia sea labrada una Capilla con un Sepulcro, en que se gastarán doze mil ducados Carlinos; y que el Cuerpo de la Devota y amada Escandalibeca, sea traído de Valencia a nuestras expensas, y honradamente sepultado en dicho Sepulcro. (...) Y más queremos que aquella devota Imagen de la Virgen Santísima Nuestra Señora que está en dicha Iglesia de la Trinidad de Valencia, que era de Doña Escandalibeca, sea traída a Nápoles, y puesta, y colocada en dicha Capilla. ${ }^{60}$

Afirma Sales que esta mujer fue enterrada en la sepultura que la familia Santángel poseía en la primera capilla del lado del evangelio de la iglesia del monasterio: "o por deudo, o amistad intima con esta misma familia valenciana que avia servido el $\mathrm{Pa}$ lacio de Nápoles"61 Debía existir ya en este momento la cripta abovedada que subsiste y que resultaría apropiada para custodiar el féretro en un enterramiento temporal, como el que unos veinte años después se dispuso en el mismo lugar para el marqués de Cenete hasta su traslación a su sepultura definitiva en la Capilla de los Reyes del Convento de Santo Domingo de Valencia. Por desgracia, saqueos e inundaciones posteriores han destruido y mezclado sin remedio los restos contenidos en esta cripta.

La tradición oral de las religiosas de la Trinidad situaba el icono de la Virgen, cerca de la sepultura, colgado en el pilar del evangelio: "el puesto, en que estuvo muchos años, del estribo de la Capilla de los Santangeles"62 en la embocadura del presbiterio, entre la sepultura de la reina fundadora, María de Castilla, y la capilla propiedad de la familia Santángel. Se dice que allí estuvo emplazado y allí se veneró, hasta su posterior traslado a una de las capillas del lado opuesto, la que hasta entonces fue de santa $\mathrm{Ana}_{1}{ }^{63}$ enclavada entre las dos puertas de acceso a la iglesia, donde ha presidido el altar hasta hoy, excepto en los periodos de conflicto bélico y ocupación del monasterio. ${ }^{64} \mathrm{La}$ razón de este traslado debió ser la convicción de que la santa imagen no sería nunca reclamada, a pesar de la disposición testamentaria de la reina napolitana, el aumento de la devoción, al atribuírsele milagros, de los que Sales relata alguno ${ }^{65}$ y la existencia de una cofradía propia...

Y qué podemos decir sobre el icono de Donica y su cofradía. Subsisten dos libros manuscritos relativos a la cofradía de la Ntra. Sra. del Refugio, ambos encuadernados en pergamino. Uno de ellos, incautado durante el proceso de desamortización eclesiástica, se encuentra en la sección de Varia del Arxiu del Regne de València; el segundo, que fue confeccionado para sustituirlo, se guarda todavía en el archivo del monasterio de la Trinidad. ${ }^{66} \mathrm{El}$ primero lleva escrito en la cubierta de pergamino, con letra del siglo XVIII: Libro que contiene el inventario, indulgencias y otros asuntos de la Cofrad $^{a}$. Sin embargo, pretende haberse comenzado a escribir en 1613, a tenor de la invocación y del título, que aparecen a partir de la quinta página, escritos en rúbrica y con letra gótica. ${ }^{67}$ Siguen diecio-

59 "Pareciole al Sumonte, que eran dignas de la Historia sus piadosas clausulas, y sacadas del original la puso en el tomo 4 , libro 6 y capitulo 7". HEBRERA, Joseph Antonio de, 1705 (véase nota 58), p. 423.

60 HEBRERA, Joseph Antonio de, 1705 (véase nota 58), p. 424.

61 SALES, Agustín, 1761 (véase nota 2), p.117.

62 SALES, Agustín, 1761 (véase nota 2), p.112.

63 "Capilla de Ntra. Sra. del Refugio. Antiguamente en esta Capilla se veneraba una Imagen de Sta. Ana, i esta era su invocación. Pero en el año 1612 habiéndose restablecido la antigua cofradía fundada en el año 1513 o antes suplicaron los cofrades al conde de la Alcudia como señor de Thous, i patrón de la Capilla, quisiesse cederla para colocar en ella la devotíssima Imagen (...) Convino dicho conde pero reservose el patronato, i puso varios pactos (...) trasladose la Sta. Imagen (...) con gran solemnidad, i desde entonces quedo a la Capilla.la invocacion que oy tiene. Reservose el Patrono la sepultura, pero en la renovación del Templo se cerro, i los cofrades tienen la suya en el medio de la lglesia, bien distinguida de las otras." Arxiu del Monestir de la Trinitat: (A.M.T.) Libro Mayor de Títulos, p. 4.

64 Sales, citando un manuscrito perdido de Fray Gerónimo Sánchez: "Al lado de la de San Antón, está la Capilla de Santa Ana, la qual era del Señor de Thous, i hoy (en 1635) de los Condes de Carlet. Está la Imagen devotissima, i milagrosa, mui frecuentada de los fieles. Es de nuestra Señora del Refugio, i tiene sus devotos Cofadría (sic). En el año 1612 fue trasladada dicha Imagen del estrivo de la Capilla primera al lado de la sepultura de la Reina (que dio al linaje de los Santangeles deudos suyos) a la del Señor Conde de Carlet que dio permisión para ello. Trasladaron la con mucha solemnidad" SALES Agustín, 1761 (véase nota 2), p. 112-113.

65 SALES, Agustín, 1761 (véase nota 2), p. 120-121.

66 A.M.T.: Capítulos de la Ilustre, Antiquísima Cofradía de ntra. Señora del Refugio de Pecadores, fundada en el convto. de Religiosas de la Sma. Trinidad. Año 1829.

67 "En nom de la Sanctissima Trinitat y de la Sanctissima Mare de Deu del Refugi de Pecadors- Any 1613" y "Memoria de les Capitulacïons q ha de tenir y côservar la Côfraria d la Mare de Deu del Refugi de Pecadors fundada en lo Côvent d Monjes de la Sanctissim Trinitat del orde dl Pre Seraphich S. Frances en Valencia". Arxiu del Regne de Valéncia, (ARV) Varia, libros: $n^{\circ} 918$ p. 5 y 7 . 
cho páginas, con escritura redondilla muy bien caligrafiada, ${ }^{68}$ con encabezados y adornos en tinta roja, donde se expresan el sistema de elección y renovación del clavario y demás cargos de la cofradía, determinando sus oficios y responsabilidades, el modo de celebración de las festividades propias, con el orden de precedencias, la relación de los enseres de su propiedad, las obras pías y otras muchos detalles y asuntos. En un momento dado se hace distinción de la existencia de 172 "cofrades de número", que se van renovando por fallecimiento o incumplimientos, siendo el resto: "cofrades de la generalitat". El libro contiene además otras anotaciones posteriores. La más significativa, que ocupa las páginas 27 y 28, presenta letra redondilla, mucho más pequeña, de excelente caligrafía y se refiere a la historia de la imagen y su cofradía; parece haber sido redactada a mediados del siglo XVIII. Siguen sin paginar: una relación de siete milagros atribuidos a la Virgen, breves notas sobre refundaciones de la cofradía y el inventario de sus bienes en 1831. También fueron encoladas al libro dos hojas de papel impreso. Unos gozos del siglo XVIII, en la parte posterior de la cubierta ${ }^{69} \mathrm{y}$ en la tercera página un recorte, que comprende una antigua estampa xilográfica de la Virgen sobre un texto impreso. ${ }^{70}$ Sobre el traslado de la Imagen desde el pilar a una capilla del lado opuesto de la iglesia se indica en este libro: "Memoria del any y dia ques tresllada la Image de ntr. Señora del refugi de Peccadors del pilar a hon estaba a la capella a hon está hara que fonch dia de Pasqua de resurrectio del any 1612 y la portaren e molt Solemne Professó y música". ${ }^{71}$

Sobre el origen de la cofradía, en las citadas anotaciones históricas, agregadas en el siglo XVIII, siguiendo por con toda probabilidad las afirmaciones de Sales, se dice que existen indicios de que había cofrades en 1503 y que en 1513 ya estaba erigida, pero que: "como de esto no hay memoria cierta que cada uno crea lo que le parezca". ${ }^{72}$ Lo que sí parece cierto, es que la cofradía debió refundarse varias veces desde 1612. Estas anotaciones recogen esa primera restauración y otra que tuvo lugar cien años después, en 1713; esta segunda probablemente por causa de los disturbios de la Guerra de Sucesión, que conllevaron el abandono y cierre temporal del propio monasterio en $1706 .^{73}$ En adelante la cofradía funcionó con intermiten-

68 Precisamente a tenor del estilo la letra, el léxico y la ortografía parece que se trate en realidad de una copia o transcripción, aunque en ninguna parte se indique. "Estes Capitulacions y ordinacions se feren y notificaren lo any Mil Siscents y tretze a Qinze de Agost dia de ntra. Señora havent fet andana los dos andadors la vespra y havensi trovat en dit Capitol los officials de dita Confraria...", ARV Varia, libros, n 918, pp. 24-25.

69 Se trata de una hoja impresa de gozos del tipo tradicional, que incluye, además de las coplillas, una estampa grabada con el aspecto que tendría el icono en esa época. A lado lleva anotada la advertencia de que se guarde con cuidado: "porque es el único ejemplar que queda." Este ejemplar difiere del que se conserva en la Biblioteca Municipal Serrano Morales en que han sido suprimidas dos estrofas relativas a la profanación de la imagen por parte de "moros" al desacreditarse esta historia. Véase nota 78.

70 El texto indica: LLibre de la Confraría de nostra Señora del Refugi de Pecadors, fundada en lo Monestir de Monjes de la Santisima Trinitat, fora los murs de la ciutat de Valencia. El recorte aparenta ser la portada de una edición impresa de un libro de la cofradía de fecha anterior, pero quizá se trate de una falsificación, dadas las diferencias estilísticas entre la imagen xilografiada y la tipografía que parece del siglo XVIII. La imagen es muy curiosa. El taco xilográfico aparenta ser de principios del siglo XVI y presenta el torso hasta las rodillas de una elegante imagen de María, con el cabello suelto y coronada. Su iconografía responde al tema de la ostentatio genitalium y así, muestra al Niño desnudo y vuelto hacia el espectador que sostiene un libro abierto y enarbola una cruz. Esta imagen está enmarcada por un mediopunto sobre columnas abalaustradas, y con decoración floral en las enjutas, donde se lee: O MATER DEI MEMANTO ME (sic). A ambos lados de la cabeza de María se pegaron dos fragmentos de papel impreso con las palabras REFUGIUM y PECCATORUM. Todo este conjunto tan raro da la impresión de constituir un falso histórico. Sobre el tema iconográfico: STEIMBERG, Leo. La sexualidad de Cristo en el arte del Renacimiento y en el olvido moderno. Barcelona: Hermann Blume ed, 1989, p. 11 y sigs.

71 "Lo Acte de la Capella de que feu mercá lo Conte de Carlet als Confrares lo rebe Bayarri. Lo acte de la concordia de les Monjes y confrares lo rebe Garcés que era llavors Syndich de les Monjes y estos dos actes se reberen en un mateix dia que fonch a Quinze de Abril del any Mil Siscents y Dotze sent clavari Vicent Çabater Ilaurador y mayorals Antoni Coronel y Andreu Iliso Ilaurador y Syndich Ilorens Geroni Ridaura notari y Abadesa del Côvent Sor Ynes Pellicer" ARV, Varia, libros: $\mathrm{n}^{\circ} 918, \mathrm{pp} .22$ y 23.

72 "hay algún fundamento de que en el citado año de 1504 ya havia cofadres (sic); pero es constante que en el año 1513 ya estaba erigida, i en el año 1517 ya se intitulava N. S. del Refugio. Dícese que antes se llamó la Virgen de Gracia, i queriendo un Poeta devoto de María SS. Hacer unos versos de alabanza de esta Señora le fue mandado en sueño la intitulasse N. S. del Refugio de Pecadores; pero como de esto no hay memoria cierta que cada uno crea lo que le parezca" ARV, Varia, libros $n^{\circ} 918$, p. 28; "En ese mismo año hai mención, i después adelante, de Cofadresas (sic) de este Convento en el citado libro de Entradas; lo que me hace sospechar, que la Cofradía del Refugio tuvo su principio, apenas la santa Imagen se colocó por esos mismos tiempos en la iglesia y se empezaron a experimentar milagros patentes", SALES, Agustín, 1761 (véase nota 2), p. 120.

73 "Restaurose la Cofradía en el año 1612 en el siguiente, se trasladó la Sa. Imagen del estrivo junto a la Capilla de Sn Miguel a la de $S^{a}$ Ana endonde (sic) oy permanece. Perdida segunda vez, se restableció el año 1713 y oy llega el numero de Cofadres (sic) a 400." ARV, Varia, libros: n 918, p. 28; Benito, Daniel, 2008 (véase nota 1), p. 166. 
cias por diversas circunstancias históricas tal como se indica en otras notas posteriores insertas en este mismo libro. ${ }^{74}$ Ya refiriéndose propiamente al origen del cuadro estas anotaciones anónimas, que atribuyo al propio Sales o quizás a Pedro Francisco Coloma, indican que:

Tan confusas dejaron los antiguos las noticias del origen de la Santa Imagen de Ntra. Sra. del Refugio, que no se sabe con certeza ni quien la trajo a esta Iglesia, ni en qué tiempo. La tradición esta tan llena de noveIlas (sic) en quanto a las circunstancias, que es preciso manifestarlas, para disuadir sus errores históricos (...) según indican los libros antiguos que guarda esta Real Monasterio, i no reconocidos hasta aora. ${ }^{75}$

Pero el relato derivado de estas investigaciones y los datos que pudiera proporcionar esta documentación inédita citada de modo tan impreciso, contiene errores históricos de bulto que lo cuestionan. Según el texto que citamos: " $D^{a}$ Beatriz, hija del Rei de Napoles Fernando I i de $D^{a}$ Juana de Aragón su Mujer hija del Rey de Aragón D. Juan II casó en primeras nupcias con Matías Rey de Hungría; muerto este casó segunda vez con Ladislao Rey de Bohemia". Pero si bien son verdad los dos matrimonios de Beatriz de Aragón, no lo es que Juana, segunda esposa de Ferrante fuera su madre, sino que lo fue su primera esposa Isabel de Chiaromonte, princesa de Tarento. De hecho Juana, nacida en 1456 y Beatriz, nacida en 1457, eran prácticamente de la misma edad; además, ambas coinciden en la fecha de su matrimonio, Juana con Ferrante y Beatriz con Matías Corvino: 1476. El relato, coincidente con el expresado por Sales en su historia del monasterio de la Trinidad, continua diciendo que Beatriz tenía a su servicio en calidad dama a "Juanota Viuda de D. Juan Castrioto hijo del gran Jorge Castrioto", y que cuando fue repudiada por su segundo marido Ladislao de Bohemia y resolvió volver a Italia: "se llevó a la Señora Juanota viuda su confidente" y en este viaje (según la tradición) encontró la imagen en alguna capilla devastada por herejes bohe- mios. ${ }^{76}$ Luego indica que "Juanota de Castrioto o Scanderbega (sic)" pasó a Nápoles: "donde estuvo en Compañía de la Reina $D^{a}$ Juana" y con ella viajó a Valencia:

En donde La Scanderbega, muerto su hijo D. Alfonso de edad de 15 años desgraciadamente, acabó su vida, según indica el libro de entradas de este RI Monasterio en mayo de 1504 i fue enterrada (...) en la sepultura de los Sant Angeles en la Capilla de San Miguel donde havia hecho colocar la $S^{a}$ Imagen en el estrivo inmediato. ${ }^{77}$

Toda esta historia es extraña y seguramente incierta, porque confunde a la esposa de Juan Castrioto con su madre Donica. Además, la esposa de Juan no se llamaba Juanota, sino Jerina Brancovic y no podía ser viuda en 1476, cuando se pretende que acompañase a Beatriz, ya que el hijo de Sanderbeg falleció en 1505. Por otra parte, en 1476, Donica fue en efecto puesta por Ferrante como dama y confidente, pero no de su hija Beatriz de Hungría, sino de su esposa, la reina Juana de Nápoles. Es por tanto dudoso que el icono fuese encontrado en Bohemia y que el desperfecto (cuchillada) que presentaba la imagen, consecuencia al parecer de una profanación, fuese causado por herejes bohemios. Sales, que en su conocida historia del monasterio, tras copiar las noticias de una crónica del P. Geronimo del Castellar, hoy perdida, relativas al hallazgo en Bohemia del icono y su profanación: "quando los Moros se apoderaron de aquel Reino" (vid. supra), intentó casar la historia de Beatriz de Bohemia con la de la Scanderberga añadió más confusión al relato. Sobre la desaparición milagrosa del desperfecto, trascribe citando dicha crónica que diversos pintores intentaron reparar sin éxito la cuchillada pero, que "cerrô" por si misma "quando a Bohemia bolvieron los Christianos". ${ }^{78}$ La misma historia se recoge en dos estrofas de los gozos que se cantaban tradicionalmente a la Virgen del Refugio, donde se hace referencia al "Moro infiel que apresó Bohe-

\footnotetext{
74 "Perdida enteramente esta Cofradía en el año 1811 por las guerras de los franceses en cuya pérdida se perdieron los efectos de mayor valor y juntamente el archivo con bulas de fundación, gracias, indulgencias y privilegios. Restaurose el año 1817 y hasta enero 1818 no se practicó nada. En el año 1823 por motivo del sitio que sufrió esta Ciudad de los realistas faltó muy poco para decaer esta cofradía...", ARV, Varia, libros, n 918, sin paginar. En 1829 se refundó la cofradía por bula de Pio VIII fechada el 28 de abril.

${ }^{75}$ ARV, Varia, libros, nº 918, p. 27.

76 “En este viaje (según la tradición) encontró la imagen santa de María SS $S^{a}$ del Refugio, en algún hermitorio, o iglesia de las que havían destruido los sequaces de Juan de Hus y Jerónimo de Praga herejes que havían infectado la Bohemia con su perversa doctrina". ARV, Varia, libros, $n^{\circ} 918$, p. 27.

77 ARV, Varia, libros no 918, p. 27.-28.

78 "Adviertese (prosigue) que esta Dama mando juntar a los mejores pintores del Reino para cubrir la cuchillada que la Virgen tenía en el rostro, i ninguno de ellos se atrevió aponer mano en ella (...) i assi quando a Bohemia bolvieron los Christianos se cerrò el señal de la cuchillada, como si no la hubiera tenido". SALES, Agustín, 1761 (véase nota 2), p. 112.
} 
mia..."79 y a la imagen que "ensangrentaron los Mauritanos furores...". Cabe recordar aquí que en ocasiones en el habla popular se denominó moros a los turcos, precisamente los enemigos de Scanderbeg, y esta inverosímil confusión entre herejes bohemios y moros nos induce a pensar que la tradición monástica sobre el origen de la imagen resultaba ya insegura y corrompida de antiguo, y también a compartir el escepticismo del anónimo autor de la anotaciones históricas del libro de la cofradía que venimos glosando.

En el año en que se trajo la $S^{a}$ Imagen tenia según la tradición, una herida en el rostro, la que no se atrevieron a componer los mejores Pintores; y se dice que se cerró después milagrosamente: pero como la historia de los moros en Bohemia es falsa, y igualmente su expulsión, se suspenda el juicio, y puede ser sucediesse el Milagro con otras circunstancias verdaderas que no dejaron por escrito los Antiguos. ${ }^{80}$

Pero vamos ya a tratar del cuadro, testigo material de estas complejas historias, y vemos que al parecer la pintura original ha llegado "milagrosamente" a nuestros tiempos, a pesar de los avatares históricos y calamidades que han ido afectando al monasterio. La Virgen del Refugio es un icono pintado sobre una gran tabla de madera, de $129 \times 73 \times 3,5 \mathrm{~cm}$, ligeramente rehundida en la parte central para que el ancho reborde resulte a modo de enmarcación, como es característico en algunos tipos clásicos de icono de tradición bizantina. Esta disposición es muy diferente, en cuanto aspecto y formato, a otros iconos antiguos valencianos como los de la Virgen de Gracia de San Agustín o la de Monteolivete. Actualmente, la figura pintada sobre el grueso soporte lígneo no es la pintura original que contempló y veneró Donica Scanderbeg, pues la tabla fue totalmente repintada al óleo según el gusto y la estética académica del primer cuarto del siglo XIX. La Virgen ha sido figurada de medio cuerpo hasta las rodillas, coronada de estrellas y vestida con una túnica violácea, velo blanco y manto en forma de maphorion azul intenso. Mira serenamente al observador y con su mano diestra entreabierta indica al Niño que sostiene con su brazo izquierdo. Este ha sido representado bendiciente, con túnica verde y manto escarlata, exhibiendo en su mano izquierda un billete donde se puede leer: Refugio de pecadores. Un vivo resplandor circunda a las dos figuras y las hace resaltar sobre el fondo pardo oscuro. En su disposición actual, aunque modernizada en el estilo, se hace patente la tipología original subyacente, que responde a la Odigitria o Virgen de Odigos, el canon iconográfico mariano más antiguo que se conoce, quizá procedente de Siria. Presenta a María indicando a su hijo como Odos (Camino). ${ }^{81}$

Las exploraciones radiológicas sobre este icono, que encargué a la doctora Pilar Ineba en marzo de 1999, no publicadas hasta ahora, han confirmado la sospecha de que debajo de la pintura actual pudiese subsistir aun la primitiva y demostrado que la imagen original no fue rascada ni destruida cuando se procedió a "restaurarla" recubriéndola con la nueva pintura académica. Su disposición, tal como puede verse en la radiografía, coincide casi totalmente con la que se ha descrito, aunque representada en le estilo propio de los iconos de tradición bizantina. El rostro de la Virgen es más enjuto y dolorido y ya no mira al observador, sino que aparece ensimismado, su mano derecha ligeramente más alzada y la forma de los plegados de los vestidos sugieren que se trate posiblemente de un ejemplar de factura oriental que quizá formase parte de un iconostasio. En la imagen radiografiada se puede apreciar que el soporte está formado en realidad por dos tablones longitudinales unidos y reforzados por dos barrotes o teleras transversales insertos en los extremos superior e inferior, más ancho el superior. La radiografía permite ver también, con gran claridad, la huella de las cuchilladas con que fue ultrajada la imagen según la tradición. Se trata de dos tajos en forma de $\mathrm{V}$ alargada que abarcan desde la parte superior hasta casi juntarse a la altura de la mano de la Virgen. Otro grave desperfecto provoca una grieta ancha con faltante desde la barbilla de la Virgen a la mano bendiciente del Niño y se alarga desde allí hasta su rodilla izquierda, más fina, pero con descamaciones. Esta exploración no ha permi-

\footnotetext{
79 "El Moro infiel apresó / á Bohemia, y a su Rey muerto / la Reyna, para el acierto / con Escandalverta huyó: / En vos libertad halló / de los barbaros horrores / Vuestro Simulacro hallaron / en un monte, el rostro Herido / y al verle tan ofendido, / el gozo en pena trocaron: / Porque en él ensangrentaron / los Mauritanos furores." A.M.T.: Gozos a la Virgen del Refugio de pecadores que se venera en el Monasterio de la Trinidad, del Orden de Santa Clara, en Valencia.

80 ARV, Varia, libros: $n^{\circ} 918$, p. 28.

81 La versión más famosa, atribuida a San Lucas, se veneró en Constantinopla en el monasterio ton dodegon (el que indica el camino) y su importancia y preeminencia le hace presidir el famoso icono del Triunfo de la Ortodoxia. DONADEO, María. Iconos de la Madre de Dios, Madrid, Ed. Paulinas, 1991, p. 37; GASSOL, Anna María. El Icono: Rostro humano de Dios: historia, arte, espiritualidad. Barcelona: Pagès editors, 1993, p. 158.
} 
tido sin embargo leer las inscripciones que, según quienes alcanzaron a verlo antes de la "restauración", figuraban en el icono.

Un texto, escrito con cuidadosa caligrafía por la entonces abadesa de La Trinidad, sor Theresa Antonia Feliu, en las primeras páginas del Libro Mayor de Títulos, ${ }^{82}$ conservado en el archivo monásti$\mathrm{CO}^{83}$ nos informa sobre los extraños caracteres inscritos, entonces visibles, en la pintura de la Virgen del Refugio, que califica de "bárbaros" como Agustín Sales "inatinables" El encabezado indica: "Explicación de los caracteres que están en la tabla o Pintura de Ntra. Sra. del Refugio" y nos informa que "con motivo de haberse quitado la vidriera que está delante del Santa Imagen (...) hallándose presente Dn. Pedro Francisco Coloma y Borja, quiso este ver de cerca la pintura, i subiendo encima del Altar observando los caracteres barbaros de plata, los copiò con toda fidelidad, i remitió la copia al Dr. Dn Agustín Sales" quien, como había acabado ya de redactar su historia del monasterio y se ocupaba por entonces de las pruebas de imprenta para su publicación, decidió no incluir esta importante referencia en su prolija y enrevesada noticia sobre el icono y su origen.

No obstante, y aun considerando las letras copiadas "inatinables, por ser mezcla de Arábigas, Griegas i Latinas", Sales se ocupó de hacer llegar la co- pia al orientalista escolapio Benito de San Pedro, quien conseguiría descifrar las inscripciones, posiblemente en caracteres grecobizantinos o cirílicos según podemos ver en la figura 10. A continuación Sales escribió una carta dirigida a sor Theresa, fechada 26 de noviembre de 1761, para informarle de los resultados de su gestión. La abadesa copió la carta aquí mismo, según la recomendación del propio Sales, pues: "convendría que para desterrar toda preocupación de os que no entienden materias tan delicadas se guardasen estos mis borrones en puesto seguro, por tener copiadas las letras de la Tabla". Al parecer además de las habituales inscripciones litúrgicas, ${ }^{84}$ que indican el nombre de las personas representadas en el icono: Jesús como "soter tou kosmou" y María como "Eleusa"85 y "Meter Zeu" -aunque el P. Benito trascribe esta última como "Uranu"- el orientalista cree poder fechar la tabla e incluso afirmar su procedencia "(in Vratislavia) Breslau"; cosas estas últimas menos aceptables. Lamentablemente hoy día es imposible comprobar su dictamen o revisarlo, ya que la tabla fue totalmente repintada, quizá en el primer cuarto del siglo XIX, tras la ocupación napoleónica del monasterio ${ }^{86}$ y a tenor de lo que indica el capítulo 21 de los estatutos de la Cofradía del Refugio redactados en $1829 .{ }^{87}$

Que Donica Castriota, la Escanderbega, la gran dama albanesa, apreciaba sobremanera a este ico-

\footnotetext{
${ }^{82}$ Este es un libro de tamaño colosal y gruesas tapas forradas de cuero, de aspecto similar al de un gran cantoral. Fue confeccionado, sustituyendo al primitivo, en 1761 para recoger actualizada y a modo de índice por orden alfabético de lugares, noticia de toda la documentación económica referente a rentas y propiedades conservada del archivo del monasterio, que había sido revisada y ordenada coincidiendo y a raíz de los trabajos históricos encargados al cronista Agustín Sales. De este modo quisieron las religiosas hacerse eco de la renovación de la archivística promovida por varios autores en el siglo XVIII. PONS ALÓS, Vicente. "Aportación a la archivística del siglo XVIII: la obra de O. Legipont y los archivos eclesiásticos valencianos". En: FAUS SEVILLA, P.; PÉREZ PÉREZ, D. (coords.). Homenaje a Pilar Faus y Amparo Pérez, Valencia: Generalitat Valenciana, Conselleria de Cultura, Educació i Ciència, 1995, p. 568.

${ }^{83}$ En las tres primeras páginas de este enorme códice, y tras un ornamentado dibujo del escudo monástico, se incluyen varios textos con interesantes informaciones y descripciones relativas a aspectos del monasterio que complementan la contemporánea historia impresa de Sales. A.M.T.: Libro Mayor de Títulos.

${ }^{84}$ En palabras de Juan Damasceno; la gracia divina es dada a las cosas materiales con la impresión del nombre de aquellos a los que el icono representa. "Escrito en el icono el nombre en el que se concentra la persona, confiere a la imagen su entidad y en el momento de la bendición final, la Iglesia verifica la presencia de la inscripción con el nombre y su correspondencia con el sujeto dibujado. El nombre expresa la hipóstasis que el fiel ve en el icono", ZIBAWI, Mahmoud. Iconos: sentido e historia. Madrid: Editorial Libsa, 1998, p. 67.

${ }^{85}$ El término Eleusa se refiere a otra tipología mariana específica, pero este título es perfectamente asumible sobre la Odigitria que representa este icono. VELMANS, Tania. "El estilo de los iconos y la regla constantinopolitana, Los Balcanes y Rusia (siglos V-XV)". En: VELMANS, T. (dir.). El mundo del icono desde los orígenes hasta la caída de Bizancio, Madrid: San Pablo, 2002, p. 52

${ }^{86}$ La tabla había estado escondida, junto a otros efectos valiosos, en casas de vecinos, personas de confianza de las monjas, durante el abandono del monasterio motivado por la inminente ocupación napoleónica, que conllevó su saqueo y graves destrucciones. BENITO Daniel, 2008 (véase nota 1), p. 177-182.

87 "Habiendo demostrado la experiencia que la principal Ymagen de nuestra Señora del Refugio de Pecadores había desmerecido en gran manera por existir en las casas de particulares sin tener en cuenta algunos gastos que se ocasionaban para tener que sacar a María Santísima, y habiendo costeado cierto devoto y algunas Religiosas para ponerla en la decencia que está en el día... A.M.T.: Capítulos de la llustre, Antiquísima Cofradía de Ntra. Señora del Refugio de Pecadores, fundada en el convto. de Religiosas se la Sma. Trinidad, Año 1829, fol. 13v.
} 
no es indiscutible. Se sabe que fue colocado sobre su sepultura en La Trinidad y que cuando la reina Juana III de Nápoles pidió en su testamento el traslado del cuerpo de su amiga no olvidó reclamar también el del cuadro, juzgándolo inseparable de la dama. Pero sobre dónde y cómo pudo obtener Donica su preciado icono no se puede hoy en día sino conjeturar. Quizá futuras investigaciones descubran más noticias y documentos sobre su oscuro origen. Ojalá se encuentre financiación para nuevas prospecciones y análisis sobre este icono que permanece como testigo físico de una historia, casi olvidada, que este texto pretendió recuperar y dilucidar. 